experiments is really phase $B$, we made some solubility determinations at $50^{\circ}$ with the pure substance. The results were $51.64,52.21$ and 52.20 . By a reference to the curve it will be seen that these values are a little too high for curve $B$, but near enough to show that phase $B$ had been obtained.

The values in the last vertical column are probably somewhat too low, since no allowance could be made for the effect of adsorption. In the third experiment the best result for phase $B$ was probably obtained, since the moist crystals were centrifuged quickly before analysis and most of the mother liquor was thus removed. The value $\mathrm{NaVO}_{3} \mathrm{I}^{3} /{ }_{4} \mathrm{H}_{2} \mathrm{O}$ obtained by this method, and the value $\mathrm{NaVO}_{3} 2 \mathrm{H}_{2} \mathrm{O}$ obtained by centrifuging alone, seem to us to show that phase $\mathrm{B}$ is $\mathrm{NaVO}_{3} 2 \mathrm{H}_{2} \mathrm{O}$. From the last two experiments in the table, we conclude that the formula of phase $\mathrm{A}$ is $\mathrm{NaVO}_{3}$.

[Contributions from the Research Laboratory of Physical Chemistry of the Massachusetts INSTITUTE OF TEChNOLOGY. No. 83.]

\title{
A SYSTEM OF QUALITATIVE ANALYSIS FOR THE COMMON ELEMENTS.
}

PART V.-DETECTION OF THE ACIDIC CONSTITUENTS. ${ }^{1}$

BY ARTHUR A. NOYES,

Received March 26, 1912.

Introduction.

This article forms a continuation of those previously published in This Journal under the same main title. ${ }^{2}$

The purpose of the investigation here described was to work out a more systematic, generally applicable plan for detecting the acidic constituents of substances than those commonly employed. The attempt was also made to develop a series of tests for the various constituents of known and roughly equal sensitiveness. Moreover, the desirability of employing methods by which an approximate estimate of the quantities present could be formed was taken into consideration, as has been done throughout this system of analysis.

The execution of this research has been made possible through the effective aid rendered by Dr. W. C. Bray, Mr. R. D. Gale, and Dr. K. G. Falk, to all of whom I wish to express my great obligation. I am indebted to Dr. W. C. Bray also for invaluable assistance in the preparation of this article for publication.

\section{General Discussion.}

I. The usual method of testing for salts of the very volatil acids consists in liberating them by heating with a stronger acid and testing the

${ }^{1}$ Copyright 1912, by Arthur A. Noyes.

${ }^{2}$ This Journal, 29, I37-205 (1907); 30, 48I-563 (1908); 31, 61 I-637 (1909). 
vapors with test papers or suspended drops of reagents. As this method gives little idea of the quantities present, it was considered inadmissible. Moreover, the usual separation of the acidic constituents from the heavier metallic elements by boiling with concentrated sodium carbonate solution is not satisfactory as a general procedure, since it fails to decompose most minerals and many other insoluble substances, since some metallic hydroxides (such as those of copper and aluminum) dissolve and separate from it upon neutralization, and since the necessity of decomposing the large quantity of sodium carbonate present in the solution makes certain tests impossible and others insufficiently delicate. A method free from these objections seemed to be the distillation of the substance with a strong non-volatil acid and collection of the distillate in water or a weak alkali solution; for this would serve to separate all the volatil acids from all the metallic elements, and would yield the former in a solution free from all other substances. A series of experiments showed in fact that a convenient and satisfactory procedure could be worked out by distilling the substance with phosphoric acid, which has been employed in quantitative analysis for a similar purpose.

This procedure must of course be supplemented by tests with fresh portions of the substance for the non-volatil acids, phosphoric and boric; for hydrofluoric acid, since this may be used up by action upon the glass; and for those acids which are decomposed by the distillation, such as thiosulfuric, hypochlorous, chloric, oxalic; but these last tests are necessary only in cases where their decomposition products have been found in the distillate.

2. The procedure finally adopted for the distillation consists in heating the solid substance in a flask with the pure $85 \%$ phosphoric acid of trade diluted with $2 \frac{1}{2}$ times its volume of water and leading the vapors into a receiver containing barium hydroxide solution, until about half the water has distilled over. Then the solution in the receiver is replaced by pure water; and the distillation is continued till the phosphoric acid becomes nearly anhydrous.

By proceeding in this way the acids divide themselves into two main groups upon the basis of the readiness with which they pass over during the distillation. The first distillate contains the readily-volatil, slightlyionized acids, namely carbonic acid, hydrosulfuric acid, sulfurous acid (from either sulfites or thiosulfates), hydrocyanic acid (from cyanides, ferro- or ferri-cyanides), nitrous acid, and free halogen (from oxyhalogen salts together with some reducing substance, or from halides together with some oxidizing substance). The second distillate contains the less volatil and largely ionized acids, namely, hydrochloric, hydrobromic, hydriodic, thiocyanic, nitric, and hydrofluoric acids; also chlorine from chlorates and carbonic acid from oxalates. 
The separation of these two groups of acids is not a perfectly sharp one. A small quantity of some of those of the second group passes into the first distillate, but never in sufficient proportion to affect the tests for them in the second distillate. Of those of the first group, hydrosulfuric acid may occasionally be found wholly in the second distillate, namely, when it is present in difficultly soluble sulfides, some of which are decomposed only after the phosphoric acid has become concentrated. Some ferrocyanides are also so slowly acted upon that the hydrocyanic acid from them is found largely in the second distillate. When treating insoluble substances, it is therefore necessary to test for these two acids in both distillates. This involves little trouble, however, and the separation of the distillate into two parts has the great advantage that the tests for sulfurous and carbonic acids in the first distillate are not interfered with by the presence of sulfuric and phosphoric acids, which may pass over in small quantity into the second distillate.

An important proportion of the sulfuric acid and of the boric acid present does not pass over even into the second distillate, provided the distillation is stopped as soon as the phosphoric acid begins to fume. By adding finely divided copper and continuing the heating, sulfuric acid is reduced to sulfur dioxide, which passes over into a "third distillate," and can be there tested for in the usual way. It was found that one milligram of $\mathrm{SO}_{4}$ could be readily detected in this way. It was thought that boric acid might also be distilled off from the phosphoric acid as methyl ester by adding methyl alcohol; but this was found not to be the case, apparently owing to the formation of a compound, boron phosphate $\left(\mathrm{BPO}_{4}\right),{ }^{1}$ with the phosphoric acid.

A disadvantage of this method of preparing the solution for the detection of the volatil acids is that certain acidic constituents in the substance, owing to decomposition, may give rise to the same product in the distillate; thus sulfites and thiosulphates both yield sulfurous acid; chlorates, hypochlorites, and chlorides (in presence of oxidizing substances), may all yield both chlorine and hydrochloric acid. When sulfurous acid or free halogen is found in the distillate, provision is therefore made (in Procedures I I 7-I 19) for testing an aqueous solution or aqueous extract of the original substance for sulfites and thiosulfates and for the oxyhalogen salts. This disadvantage, however, is compensated by the fact that the distillation shows whether special tests for these constituents are necessary, which, owing to their comparatively rare occurrence, is seldom the case.

3. The plan of analysis of the separate distillates may be seen in outline by reference to Tables XI and XII on the following pages. These outlines will not only serve to give the general reader a survey of the pro-

${ }^{1}$ Cf. Mylius and Meusser, Ber., 37, 397 (1904). 
cess, but they should be frequently referred to by any one employing the scheme for the first time, in order that the principles involved may be clear and the various procedures properly correlated.

The first distillate is collected in barium hydroxide solution, because loss of very volatil acids, like carbonic acid, is thereby avoided, and because the non-formation of a precipitate at once shows the absence of two acids of the group, carbonic and sulfurous acids. The detection of these two acids in the presence of each other and their separation from the other acids is complicated by the difficulty of filtering out their barium precipitates so as to yield a clear filtrate. To obviate this difficulty the plan was worked out in detail in the manner shown in Table XI and in Procedure 102. The presence or absence of another group of acids, namely, of nitrous acid and those acids yielding free halogens, is then shown by the addition of chloroform followed by that of potassium iodice.

Special tests for nitrite, sulfide, and cyanide are provided for. That employed for nitrite is the evolution of nitrogen by the action upon urea, which in acid solution is highly characteristic. Sulfide is tested for in acetic acid solution by the addition of a cadmium salt. Cyanide is detected in the usual way by its conversion into ferric ferrocyanide. Provision is also made for determining whether the hydrocyanic acid in the distillate originated from a readily decomposable cyanide or from a ferro- or ferricyanide; namely, by warming the original substance with a solution containing free carbonic acid (which displaces the hydrocyanic acid from simple and most complex cyanides, but not from the relatively stable ferro- and ferricyanides), and testing for hydrocyanic acid in the distillate.

4. In the analysis of the second distillate, silver nitrate and nitric acid are first added to determin the absence or presence of the acids that give a precipitate with silver salts; and then such special tests are applied as may still be necessary.

For the detection of chlorine in the presence of the other halogens, the method of distillation with sulfuric acid and bichromate was. rejected, because of its lack of delicacy, because of the necessity of working with the dry substance, and because of the inconvenience which it involves. The method adopted is similar to that worked out by Jannasch ${ }^{1}$ and Küster, ${ }^{2}$ which is based on the successive liberation of the iodine and bromine by permanganate by producing the proper hydrogen-ion concentration in the solution and on their removal by boiling. This method was investigated in this laboratory by Dr. W. C. Bray and Mr. R. D. Gale, and was modified so as to make the tests for iodide and bromide more simple and delicate. The modification consisted in adjusting the acid concen-

3 $Z$. anorg. Chem., I, I44, 248 (I892).

'See Crotogino, Z. anorg. Chem., 24, 23 I (rgoo). Böttger, Qual. Anal, 387 (1908). 
trations so that iodine and bromine were successively liberated at room temperature and in shaking them out into a solvent such as chloroform. ${ }^{1}$

For the detection of nitric acid the usual ring test with ferrous sulfate and sulfuric acid was found not to be delicate enough to detect even five milligrams with certainty. The highly characteristic and delicate test based on its reduction to nitrous acid by boiling with ferrous sulfate and on the reaction of the nitrous acid in the distillate with potassium iodide was therefore adopted.

5. As stated above, supplementary tests must be made with the original substance in cases where sulfurous acid is found in the first distillate or where chlorine is found in either the first or second distillate, to determin the nature of the acidic constituents from which these substances originated. For these tests the solution is prepared by treating the substance either with water or (in order to free it from precipitable bases) with sodium carbonate solution, filtering, and acidifying slightly with acetic acid.

For the detection of sulfite and thiosulfate in this solution the method of Autenrieth and Windaus ${ }^{2}$ is used, which is based on the fact that sulfite is precipitated by strontium nitrate, while thiosulfate is not. The latter constituent is then readily detected in the filtrate by the separation of sulfur which occurs on adding hydrochloric acid.

For the detection of hypochlorite, its characteristic power of oxidizing lead salts to brown lead dioxide is made use of. Chlorate is detected in the presence of hypochlorite or halides by reducing the former to chloride with sodium arsenite, precipitating all the halide present by silver nitrate, filtering, and adding sulfurous acid to the filtrate to reduce the chlorate to chloride.

Supplementary tests for certain non-volatil acidic constituents and for fluoride are also provided for. Phosphate, if not already detected in the analysis for the basic constituents, is tested for in nitric acid solution in the usual way with ammonium molybdate. The most satisfactory method of testing for boric acid, so as to afford at the same time a rough estimate of its quantity, seemed to be to heat the dry substance with methyl alcohol and sulfuric acid, to collect the distillate in a mixture of methyl alcohol and concentrated hydrochloric acid, and to add to it turmeric solution. ${ }^{3}$ Under these conditions an orange or red color results when borate is present. Fluoride is tested for by the Berzelius method of heating the dry substance in a tube with finely divided silica and acid potassium sulphate, and noting whether a deposit of silica forms on the cold part of the tube.

${ }^{1}$ Compare the volumetric method of titrating iodide described by Bray and MacKay, This Journal, 32, I 193 (I9IO).

${ }^{2} Z$. anal. Chem., 37, 290 (1898). See Böttger, Qual. Analyse, 382 (1908).

${ }^{3}$ A quantitative method based on this color reaction has been described by Hebebrand (Z. Nahr. und Genussm., 5, 56 (1902)). 
Finally provision is made for analyzing silicates and other substances that are not decomposed in the phosphoric acid distillation, by fusing them with sodium carbonate and testing the aqueous extract for the acidic constituents that are likely to be present, namely for silicate, sulfate, phosphate, borate, fluoride, and chloride.

6. As has been done throughout this System of Analysis, the process has been described in such a way as to provide for the case that every constituent is present, it being left to the analyst to shorten it when certain constituents are proved absent in the course of the analysis or when information in regard to the character and source of the material excludes their presence. This method of presentation of ten makes the process seem longer than it is in practice; and this is especially true of this part which treats of the detection of the acidic constituents; first, because many of these are mutually exclusive, like hydrosulfuric, sulfurous, and nitrous acids, and free halogens; secondly, because the nature of the metallic element considered in connection with the solubility of the substance often makes the presence of certain of them impossible; and thirdly, because the nature of source of the substance, especially when it is a mineral or metallurgical product, excludes many of them.

7. Attention may finally be called to a simple modification of this plan for detecting the acidic constituents which it may be thought preferable to adopt as the general procedure, and which at any rate it may be advisable to employ in the analysis of certain classes of substances, for example of minerals not much acted upon by acids. The modification referred to consists in using the phosphoric acid distillation only for detecting the very volatil or readily decomposable acids (carbonic, hydrosulfuric, sulfurous, hydrocyanic, nitrous, and oxyhalogen acids), and in testing for the other acids (hydrochloric, hydrobromic, hydriodic, nitric, chloric, oxalic), which pass over (as such or as decomposition products) into the second phosphoric acid distillate, not in that distillate, but in an acid solution prepared directly from the original substance (or from a fusion of it with sodium carbonate). This is possible, since the tests for these last acidic constituents can all be made in acid solution, and since they are not interfered with by the presence of basic constituents. This modification might considerably simplify the formal description of the procedure and facilitate its comprehension by beginners. Attention is called to it also for the sake of emphasizing the ideas that the distillation procedure is especially valuable for detecting the readily volatil acids, and that, whether or not it is well to adopt it entirely, it affords a far more satisfactory method of testing for those acids than does the usual plan of liberating them in an open tube by warming with hydrochloric or concentrated sulfuric acid and examining the vapor as to its odor or color or as to its effect on test papers or suspended drops of liquids. 


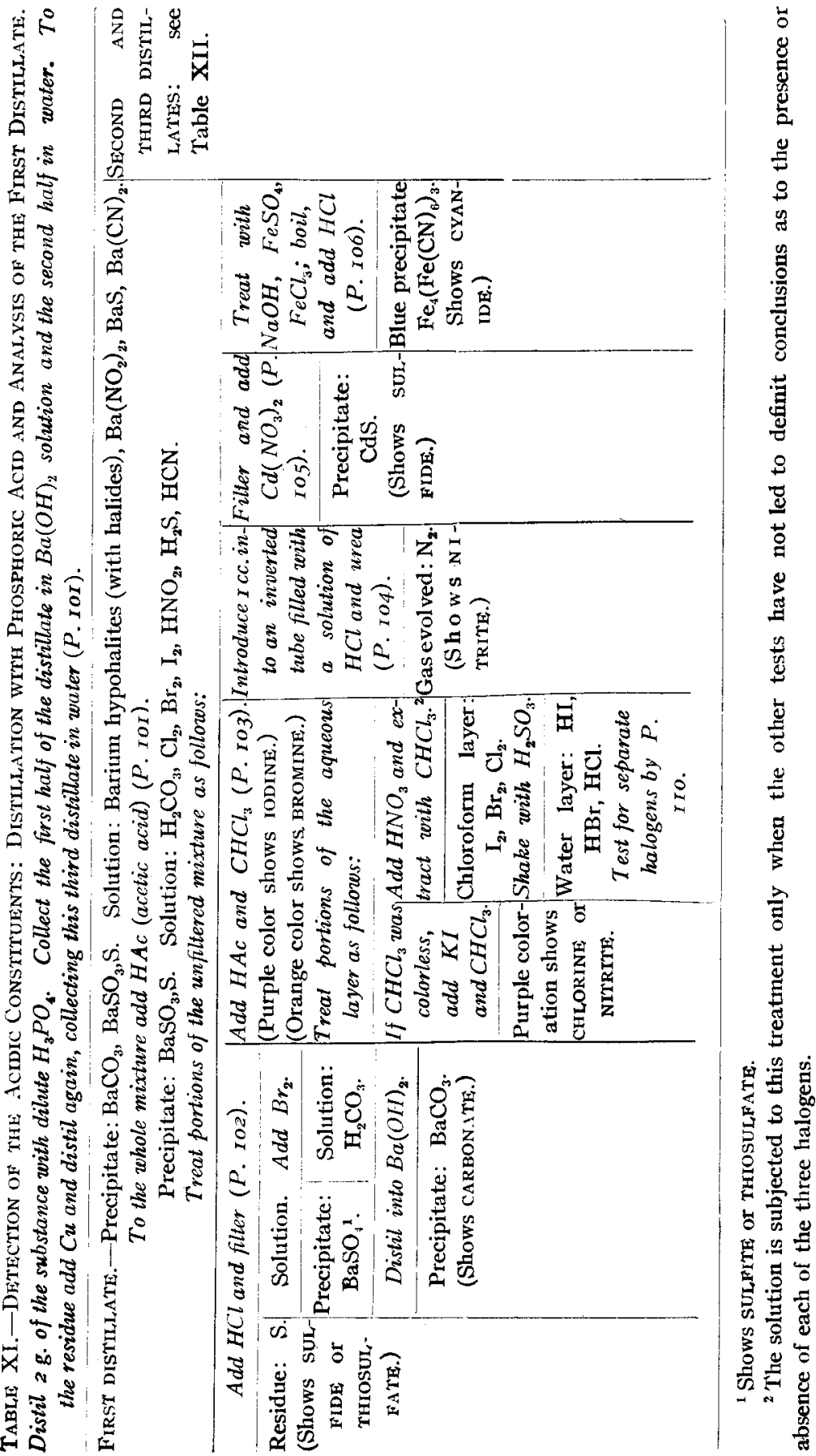




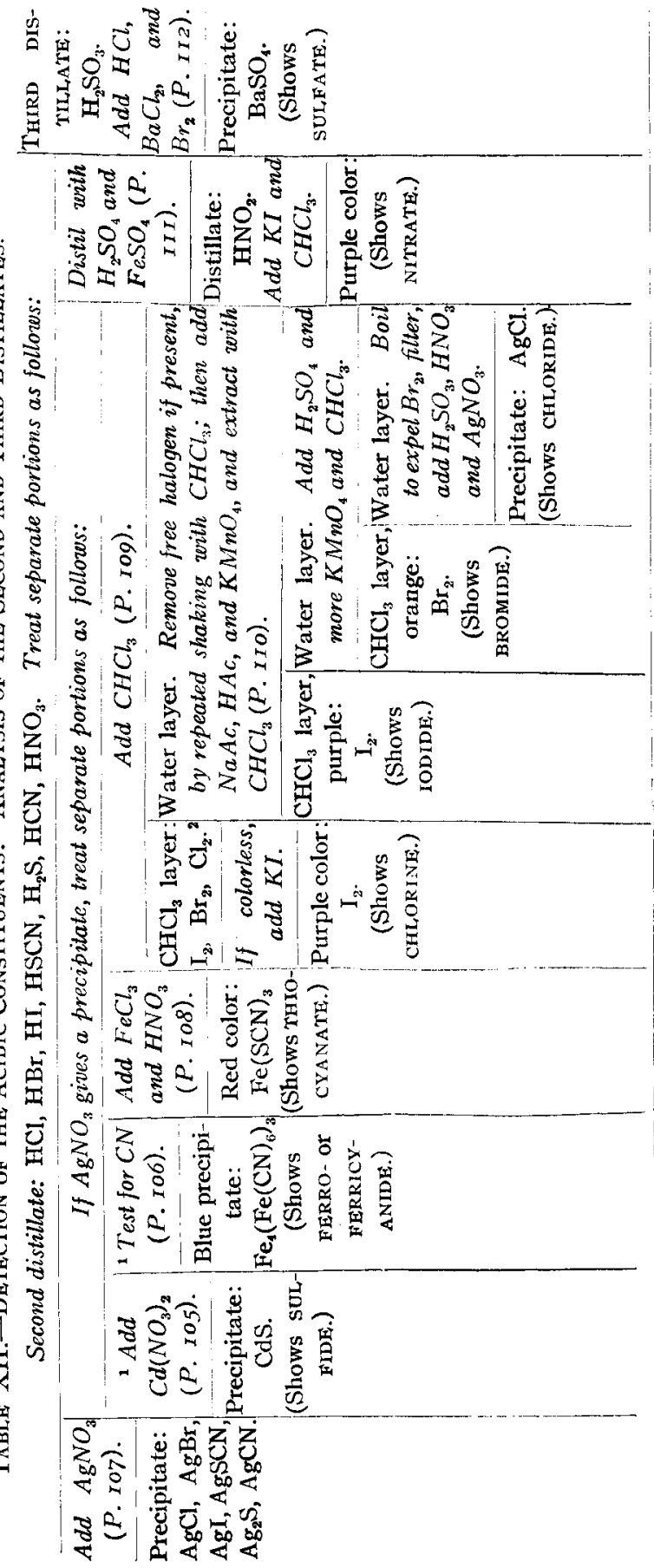




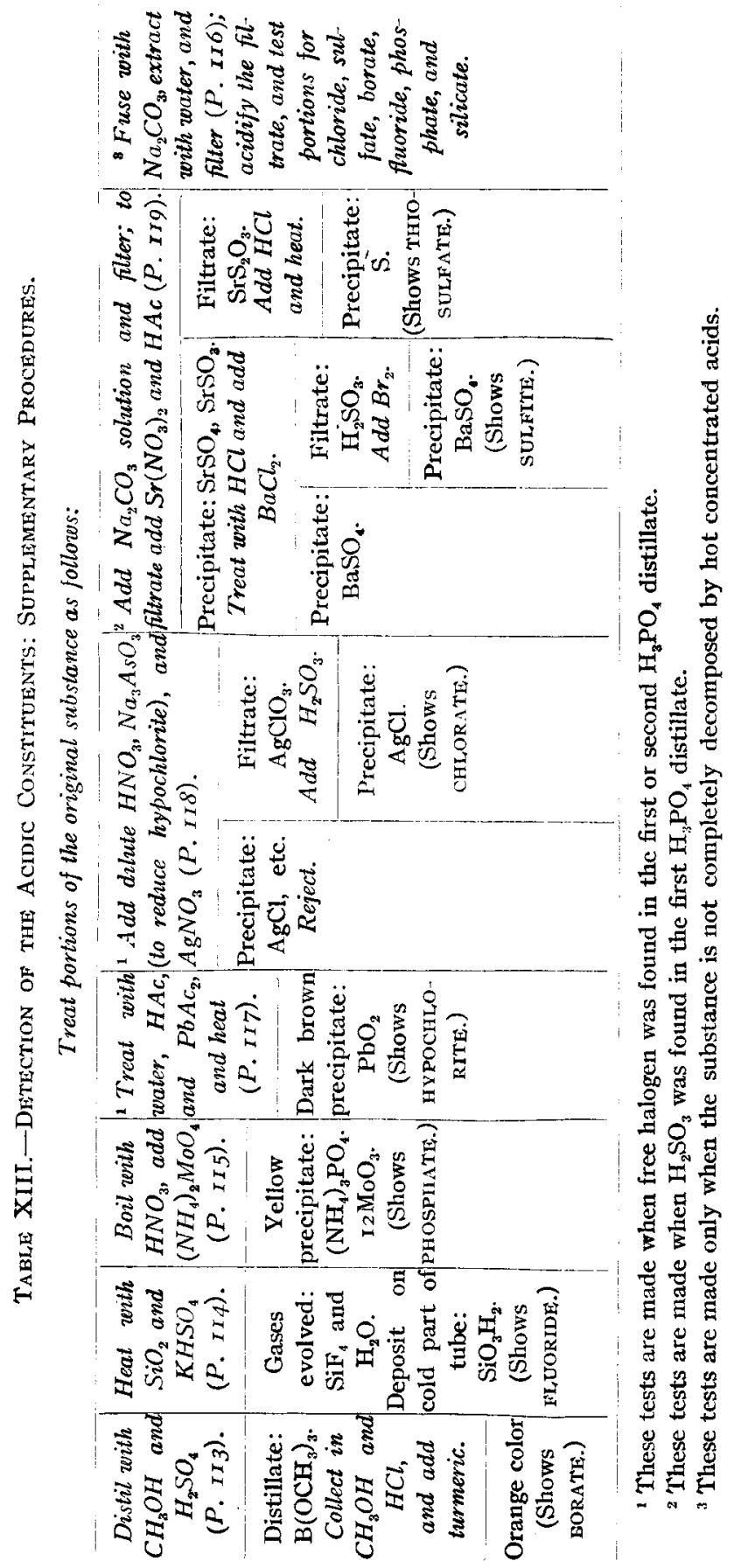




\section{Procedures and Notes. \\ Distillation with Phosphoric Acid.}

Procedure Ior.-Place 2 grams of the finely powdered substance and a few glass beads in a $100 \mathrm{cc}$. round bottomed Jena flask fitted with a rubber stopper through which pass a straight tube $20-30 \mathrm{~cm}$. long leading to the bottom of the flask and a delivery tube. Fasten the flask in position at an angle of about $60^{\circ}$. Lead the end of the delivery tube through a two-hole stopper into $40 \mathrm{cc}$. of nearly saturated $\mathrm{Ba}(\mathrm{OH})_{2}$ solution contained in a $100 \mathrm{cc}$. flask supported in a large beaker of cold water. Boil in a small flask for about a minute a mixture of $25 \mathrm{cc}$. water and ro cc. $85 \% \mathrm{H}_{3} \mathrm{PO}_{1}$ (to expel any $\mathrm{CO}_{2}$ present in it). Pour this mixture into the distilling flask with the aid of a small funnel connected with the long, straight tube. Heat the mixture to boiling, distil till about ro cc. have passed over, and then remove the distillate. (White precipitate, presence of carbonate or some sulfur-containing constituent.)

Cool the distillate and make it slightly acid with acetic acid. (Complete or partial solution of the precipitate, presence of carbonate; residue ( $\mathrm{S}$ or $\mathrm{BaSO}_{3}$ ), presence of free sulfur, sulfide, sulfite, or thiosulfate) ${ }^{1}$. If there is a residue, treat one-half of the mixture immediately by P. IO2, and separate portions of the remainder by P. I03, 104, 105, and 106. If there is no residue, treat separate portions of the whole distillate by $\mathrm{P}, \mathrm{IO} 3, \mathrm{IO4}, \mathrm{I0} 5$ and 106.

Introduce the end of the delivery tube of the distilling flask into another receiver containing $35 \mathrm{cc}$. water. Continue the distillation until the phosphoric acid becomes syrupy, boils more quietly, and begins to give off fine white fumes. Treat this distillate as directed in P. 107.

To the contents of the distilling flask, while still warm, add 5-ro grams of copper filings or turnings. Distil for 3-5 minutes longer, collecting the distillate in $15 \mathrm{cc}$. of water. Note the odor of the distillate, and treat it by P. II2.

Notes.-1, Since many of the tests for the different acids must be made in separate portions of the distillate, a larger sample is taken than for the analysis of the metallic elements, in order that detectable amounts may be present in these separate portions.

2. It is necessary to use a Jena glass flask, since one of ordinary glass is quickly destroyed by the action of hot, concentrated phosphoric acid. The boiling is sometimes violent, especially when much insoluble material is present. The addition of the glass beads serves to reduce the bumping; and placing the flask in a slightly inclined position prevents material from being thrown over into the distillate, which would lead to error in the subsequent tests. In any case in which it seems possible that some of the boiling liquid has been thrown over into the distillate, a small portion of the latter shouid be tested for phosphate by adding an equal volume of $\left(\mathrm{NH}_{4}\right)_{2} \mathrm{MoO}_{4}$ solution (see P. I I5).

3. The point at which the second distillation should be stopped is fairly distinct.

${ }^{1}$ Such statements always refer to the presence of the constituent in the original substance, unless otherwise stated. 
The chief indications of this point are that the phosphoric acid has become syrupy, that the boiling takes place more quietly, and that a hotter flame is required to maintain it. Also fine white fumes usually begin to appear, but they are not always plainly visible.

4. The saturated $\mathrm{Ba}(\mathrm{OH})_{2}$ solution in which the first distillate is collected is best prepared by adding 40 grams of the commercial crystallized hydrate to $500 \mathrm{cc}$. of boiling water, boiling 2 or 3 minutes, allowing the solution to cool and stand over night in a high, narrow vessel, and siphoning off the clear solution. The solution should, of course, be protected from the air as much as possible during the whole process. A mixture of $\mathrm{BaCl}_{2}$ and $\mathrm{NH}_{4} \mathrm{OH}$ can not well be substituted for the $\mathrm{Ba}(\mathrm{OH})_{2}$, since the ammonium acetate produced by the subsequent neutralization prevents the precipitation of a small quantity of $\mathrm{BaCO}_{3}$.

5. Phosphoric acid, which is ionized into $\mathrm{H}^{+}$and $\mathrm{H}_{2} \mathrm{PO}_{4}^{-}$to a moderate extent (about $27 \%$ in 0.1 molal solution), displaces almost completely from their salts (unless these are very difficultly soluble) the much less ionized acids, $\mathrm{H}_{2} \mathrm{CO}_{3}, \mathrm{HNO}_{2}$, $\mathrm{H}_{2} \mathrm{~S}, \mathrm{HClO}, \mathrm{HCN}, \mathrm{HF}$, and $\mathrm{H}_{3} \mathrm{BO}_{3}$, and also to a large extent the moderately ionized $\mathrm{H}_{2} \mathrm{SO}_{3}$. Since all these acids, except $\mathrm{HF}$ and $\mathrm{H}_{3} \mathrm{BO}_{3}$, volatilize readily out of aqueous solution, they pass over almost or quite completely into the first distillate, $\mathrm{HClO}$ in the presence of chloride giving $\mathrm{Cl}_{2}$. The largely ionized acids, $\mathrm{HCl}, \mathrm{HBr}, \mathrm{HI}, \mathrm{HSCN}$, $\mathrm{HNO}_{3}, \mathrm{HClO}_{3}, \mathrm{H}_{3} \mathrm{Fe}(\mathrm{CN})_{6}$, and $\mathrm{H}_{4} \mathrm{Fe}(\mathrm{CN})_{6}$, are not found in any considerable proportion in the first distillate, since they are displaced from their salts much less completely, and since in addition they are much less volatil. Of these the first five pass over unchanged and almost completely into the second distillate; for after the $\mathrm{H}_{3} \mathrm{PO}_{4}$ has become fairly concentrated, the acids are displaced to a greater extent and volatilize more readily in consequence of the higher temperature at which the mixture boils and the smaller proportion of water it contains. From the stronger $\mathrm{H}_{3} \mathrm{PO}_{4}$ solution $\mathrm{HF}$ also passes over in large quantity; but this is not true of $\mathrm{H}_{3} \mathrm{BO}_{3}$ and $\mathrm{H}_{2} \mathrm{SO}_{4}$, which volatilize only in insignificant amounts even when the acid has become nearly anhydrous. The three acids, $\mathrm{HClO}_{3}, \mathrm{H}_{4} \mathrm{Fe}(\mathrm{CN})_{6}$, and $\mathrm{H}_{3} \mathrm{Fe}(\mathrm{CN})_{6}$, are not volatil as such, but are decomposed by the $\mathrm{H}_{8} \mathrm{PO}_{4}$ after it becomes fairly concentrated- $\mathrm{HClO}_{3}$ with formation of $\mathrm{Cl}_{2}$ and $\mathrm{HCl}, \mathrm{H}_{2} \mathrm{Fe}(\mathrm{CN})_{6}$ and $\mathrm{H}_{4} \mathrm{Fe}(\mathrm{CN})_{6}$ with formation of free $\mathrm{HCN}$. In regard to the acids that may be present in the two distillates, see also G. D., Section 2, and Tables XI and XII.

6. The barium salts of all the acids passing into the first distillate, except the carbonate and sulfite, remain in solution. Phosphoric acid, if thrown over mechanically, would, however, also give a precipitate. Sulfur, when present in the free state or when liberated from a polysulfide or thiosulfate, volatilizes with the steam, and gives a turbid appearance to the water condensed in the delivery tube and to the barium hydroxide solution, by which it is little acted on in the cold. Chlorine is converted by the barium hydroxide into barium chloride and hypochlorite; bromine, into bromide, hypobromite, and bromate; and iodine, mainly into iodate and iodide.

7. On acidifying the first distillate slightly with acetic acid, $\mathrm{BaCO}_{3}$ dissolves, but $\mathrm{BaSO}_{3}$ does not. This difference in behavior is due to the fact that hydrocarbonateion $\left(\mathrm{HCO}_{\mathrm{a}}{ }^{-}\right)$is much less ionized than hydrosulfite-ion $\left(\mathrm{HSO}_{3}^{-}\right)$. Sulfur, if present, also remains undissolved. The addition of acetic acid causes the liberation almost at once of chlorine, bromine, or iodine from a mixture of hypochlorite and chloride, hypobromite and bromide, or iodate and iodide; but bromine is set free somewhat more slowly from a mixture of bromate and bromide.

8. A small precipitate obtained in this procedure (or in the following one) does not prove the presence of carbonate in the mixture unless the prescribed precautions are carefully observed-namely, the boiling of the onginal phosphoric acid solution, and avoiding the exposure to the air of the various solutions, especially that of barium 
hydroxide. Even with these precautions, however, it is seldom possible to prevent the absorption of enough carbon dioxide to produce a slight turbidity in the barium hydroxide solution.

9. Upon boiling the $\mathrm{H}_{3} \mathrm{PO}_{4}$ with the copper, $\mathrm{H}_{2} \mathrm{SO}_{4}$, if present, is reduced to $\mathrm{H}_{2} \mathrm{SO}_{3}$; and this passes over into the distillate in the form of $\mathrm{SO}_{2}$ gas. Less than $\mathrm{I} \mathrm{mg}$. $\mathrm{SO}_{4}$ can be detected by this process of distillation. The copper should be finely divided and should be added while the liquid is still warm, since on cooling it solidifies to a glassy mass, which consists of pyrophosphoric acid $\left(\mathrm{H}_{4} \mathrm{P}_{2} \mathrm{O}_{7}\right)$. The heating should be continued for 5-Io minutes; but, if much more prolonged, the contents of the flask change to a solid mass, owing to conversion of the pyro to metaphosphoric acid $\left(\mathrm{HPO}_{3}\right.$, which can afterwards be removed only with much difficulty.

ro. With reference to the analysis of the first and second distillate, provided for in the subsequent procedures, certain facts are to be noted which in many cases greatly reduce the number of these special tests which it is necessary to make. In the first place, some of the acids are incompatible with each other, so that when certain ones are found, others need not be tested for: thus in the acidified distillate $\mathrm{H}_{2} \mathrm{~S}$ can not be present with $\mathrm{H}_{2} \mathrm{SO}_{3}, \mathrm{HNO}_{2}$, or free halogen; $\mathrm{HNO}_{2}$ and $\mathrm{H}_{2} \mathrm{SO}_{3}$ can not be associated with each other or with free halogen, etc. Secondly, the nature of the metallic elements taken in connection with the solubility of the substance of ten excludes certain acidic constituents; thus in a substance containing barium and soluble in water or very dilute acid, sulfate can not be present; in a water-soluble substance containing silver, none of the acids precipitated by silver nitrate can be present. Thirdly, the general character or known source of the substance may make many of the tests unnecessary; thus, it is useless to test a mineral for nitrite, sulfite, oxyhalogen salts, simple or complex cyanides, oxalate, or other organic salt. The analyst should, therefore, always consider these aspects of the problem, shortening the procedure in such ways as his knowledge makes possible.

\section{Analysis of the First Distillate.}

Procedure I02.-Detection of Carbonate and Sulfur-containing Constituents.-To one-half of the first distillate (P. IOI), if there was a residue on adding acetic acid, add I-2 cc. $\mathrm{HCl}$ (I. I2). (Residue, presence of free sulfur, sulfide, or thiosulfate.) Filter, and add to the filtrate saturated bromine solution till the liquid becomes slightly yellow. (White precipitate, presence of sulfite or thiosulfate.) Transfer the mixture to a distilling apparatus such as is used in P. IOI, first filtering out the precipitate if it is large, distil for a minute or two, collecting the vapors in 20 cc. saturated $\mathrm{Ba}(\mathrm{OH})_{2}$ solution. (White precipitate, presence of carbonate.) Acidify slightly with acetic acid. (Solution of the precipitate, presence of carbonate.)

If $\mathrm{H}_{2} \mathrm{SO}_{3}$ is found in the distillate, treat a fresh portion of the original substance by P. I 9 , to determin whether it comes from a sulfite or thiosulfate.

Notes.-I. See P. IOI, N. 6-8. Since $\mathrm{H}_{2} \mathrm{SO}_{3}$ slowly oxidizes to $\mathrm{H}_{2} \mathrm{SO}_{4}$ in the air, the solution should be treated with $\mathrm{HCl}$ at once. If any $\mathrm{H}_{2} \mathrm{SO}_{4}$ has been formed in this way, it will be precipitated as $\mathrm{BaSO}_{4}$ before the addition of $\mathrm{Br}_{2}$. Care must be taken to add enough $\mathrm{Br}_{2}$ to complete the oxidation, since otherwise in the subsequent distillation $\mathrm{SO}_{2}$ will distil over and might be mistaken for carbonate. 
2. If there is a large precipitate of $\mathrm{BaSO}_{4}$, it is filtered out, since otherwise it is difficult to avoid violent bumping during the distillation. Exposure to the air should, however, be avoided so far as possible, so that $\mathrm{CO}_{2}$ may not be absorbed from it.

3. A residue of sulfur may arise from the presence in the substance of free sulfur, of a persulfide, of an ordinary sulfide together with some oxidizing substance, or of a thiosulfate.

Procedure 103.-Detection of Nitrite and Constituents Yielding Free Halogen.--To one-fourth of the first distillate (P. IOI), or of what remains of it (P. IO2), add I-2 cc. $30 \%$ acetic acid and 2-3 cc. of chloroform, and shake vigorously. (Furple coloration of the chloroform, presence in the distillate of free iodine; yellow or orange coloration, of free bromine.)

If there is no coloration, pour about a third of the aqueous layer into a test tube, add I cc. chloroform and a few drops I\% KI solution, and let the mixture stand for 5 minutes, noting whether the color due to liberated iodine increascs. (Purple color, presence in the distillate of chlorine or nitrous acid; no color, absence of nitrite in the substance.)

If there is a coloration after the addition of $\mathrm{KI}$, test a I cc. portion of the first distillate (P. IOI) for nitrite by P. IO4.

If these tests show the absence of nitrite and the presence of free halogen, but do not warrant definit conclusions as to the presence or absence of each one of the three halogens, proceed as follows: Add $5 \mathrm{cc}$. $\mathrm{HNO}_{3}$ (I.2O) to the remaining two-thirds of the aqueous layer, separate the chloroform from it by means of a separating funnel, shake that layer a second and third time with $3 \mathrm{cc}$. of fresh chloroform, and separate the layers sharply again. Unite the three portions of chloroform, wash it once in the separating funnel by shaking it with about one-third its volume of $\mathrm{HNO}_{3}$ (r.05), add the chloroform to an equal volume of $\mathrm{H}_{2} \mathrm{SO}_{3}$ solution in a separating funnel, shake, draw off and reject the chloroform layer, and test the aqueous layer for bromide and chloride•by $P$. I ro.

If free halogen is found present in the distillate, treat fresh portions of the original substance for hypochlorite by P. I I 7 and for chlorate by P. II8.

Notes.-I, For the reactions between the halogens and barium hydroxide and their reformation on acidifying with acetic acid, see P. IOI, N. 6 and 7 .

2. The free halogens distribute themselves between the chloroform and water phases. In the case of pure bromine or iodine the ratio of the concentration in the chloroform to that in the water layer is very large and is almost independent of the concentration. This is in accordance with the so-called distribution law, which requires that the ratio of the concentrations of a given molecular species, such as $\mathrm{Br}_{2}$ or $\mathrm{I}_{2}$, in the two solvents be constant. When an iodide, like HI, is also present, the proportion of iodine extracted by the chloroform is greatly reduced, since the iodine in the aqueous layer is largely combined with the iodide in the form of the triiodide $\left(\mathrm{HI}_{3}\right)$; but it is still sufficient to make the color test a very delicate one.

3. The characteristic purple color given to chloroform is so delicate a test that even $0.05 \mathrm{mg}$. of iodine in the solution tested can be detected by this procedure. Bromine may be detected, but only in the absence of iodine, by the orange or yellow color 
of the chloroform layer when not less than $0.5 \mathrm{mg}$. of bromine is present in the solution tested. (If a few drops of KI solution be added to one-third of the chloroform layer, the more intense color of the iodine liberated will enable a smaller quantity of bromine to be detected.) Chlorine gives no decided color to the chloroform, but like bromine causes liberation of iodine on the addi ion of KI. For extracting the halogens from aqueous solutions carbon tetrachloride or carbon disulfide may be used instead of chloroform; but carbon disulfide has the disadvantage of being highly inflammable.

4. Nitrous acid, like bromine or chlorine, liberates iodine from KI. The reaction is delicate enough to enable o.I mg. $\mathrm{NO}_{2}$ to be detected in the solution tested. A peculiarity of this reaction is that the nitric oxide which is form-d by it is rapidly reoxidized by the oxygen of the air to nitrous acid, which then reacts with the iodide so that a continuous liberation of iodine results. Thus the nitrous acid acts as a catalyzer of the reaction between oxygen and HI. This progressive liberation of iodine is highly characteristic of nitrous acid, but renders it difficult to estimate the amount of it present. Since this behavior may not be a conclusive indication of nitrous acid, a fresh portion of the distillate is tested for it by P. 104.

5. If nitrous acid is found in the distillate, it shows the absence of free halogens, since nitrous acid is oxidized by chlorine or bromine very rapidly at room temperature and by iodine during the distillation with phosphoric acid.

6. An aqueous solution of chlorine contains a considerable proportion of $\mathrm{HClO}$ and $\mathrm{HCl}$, sufficient to satisfy the equilibrium conditions of the reaction $\mathrm{Cl}_{2}+\mathrm{H}_{2} \mathrm{O}=$ $\mathrm{HClO}+\mathrm{H}^{+}+\mathrm{Cl}^{-}$. Since the proportion present as $\mathrm{Cl}_{2}$ decreases with decreasing hydrogen-ion concentration, and since only the $\mathrm{Cl}_{2}$ dissolves in the chloroform, the quantity of chlorine extracted from a nitric acid solution must, in accordance with the distribution law, be much larger than from an acetic acid solution. In order, however, to extract small amounts of chlorine nearly completely it is necessary to add chloride as well as the acid.

7. When free halogen is detected by these tests it shows either that the halogen was present in the original substance in the free state, or (what is more common) that it was liberated during the distillation with phosphoric acid, from a halide by the action of some oxidizing substance, or from an oxyhalogen salt (such as a hypochlorite, chlorate, bromate, etc.), by spontaneous decomposition or by reaction with some reducing substances. When free halogen is found in the distillate, a portion of the original substance is therefore further tested (by $P$. 117 and 118 ) to determin from what source the halogen originated.

Procedure r04.-Detection of Nitrite.-If the results, of P. IO3 show that the first distillate may contain $\mathrm{HNO}_{3}$, determin its presence or absence as follows: Fill a weighing tube with a $20 \%$ solution of urea in $\mathrm{HCl}$ ( I. I2), and invert it over a small dish containing more of the same solution. Introduce I $\mathrm{cc}$. of the first distillate (P. IOI) into the weighing tube by means of a small tube which has one end closed with a rubber nipple and the other end drawn out and bent so as to form a small $U$. Take care not to introduce an air bubble at the same time. (Formation of gas, presence of nitrite.)

Notes.-r. The reaction between urea and nitrous acid is $\mathrm{CO}\left(\mathrm{NH}_{2}\right)_{2}+2 \mathrm{HNO}_{2}=\mathrm{CO}_{2}+2 \mathrm{~N}_{2}+3 \mathrm{H}_{2} \mathrm{O}$.

The $\mathrm{N}_{2}$ is liberated in the form of minute bubbles which collect at the top of the tube. When much $\mathrm{CO}_{2}$ is produced, it also separates as a gas; but a small quantity remains dissolved in the liquid. The amount of nitrite present may be estimated by making a comparative test with a known quantity of nitrite. 
2. This procedure enables $0.1 \mathrm{mg}$. $\mathrm{NO}_{2}$ in the $1 \mathrm{cc}$. of solution tested to be detected; but since such a small portion of the distillate is used a more delicate test may be desirable. If so, make a larger amount of the distillate slightly alkalin with $\mathrm{NaOH}$, evaporate it to about $\mathrm{I}$ cc., acidify with a drop or two of $\mathrm{HCl}$, and treat this solution as described in the procedure. In this process, before evaporating the solution, it is made alkalin so as to avoid loss of $\mathrm{HNO}_{2}$. The mixture is afterwards acidified so that carbonic acid may be expelled from it before it is introduced into the tube.

3. The halogens, chlorine, bromine, and iodine, when dissolved in alkali decompose urea with evolution of nitrogen, but they do not do so when dissolved in concentrated $\mathrm{HCl}$. They do not therefore interfere with the test when carried out as above described.

4. Since all nitrites are at least moderately soluble in water, this test may be made with an aqueous solution or aqueous extract of the original substance. The test should be so made when the nature of the substances present makes it possible that nitrous acid may have been completely decomposed during the distillation with $\mathrm{H}_{3} \mathrm{PO}_{4}$.

Procedure 105.-Detection of Sulfide.-To one-half of what still remains of the first distillate (P. IOI), add 2 cc. I0\% $\mathrm{Cd}\left(\mathrm{NO}_{3}\right)_{2}$ solution. (Yellow precipitate, presence of sulfide.)

Notes.- $-\mathrm{I}$ : The presence of $\mathrm{H}_{2} \mathrm{~S}$ is usually detected in the distillate by its odor; but the precipitation of CdS from a weakly acid solution has the advantage of enabling the amount of sulfide to be approximately estimated. When this test is applied to a strongly acid solution from any other source, sodium acetate should also be added.

2. A negative test for $\mathrm{H}_{2} \mathrm{~S}$ in the first distillate does not prove the absence of sulfide in the original substance, unless the latter has dissolved completely in the dilute $\mathrm{H}_{3} \mathrm{PO}_{4}$; for some difficultly soluble sulfides, such as $\mathrm{CuS}$, are decomposed only when the $\mathrm{H}_{3} \mathrm{PO}$, becomes concentrated, as it does in the latter part of the distillation. It is therefore directed in P. IO7 and I I 2 to test also the second and third distillates for sulfide.

Procedure I06.-Detection of Cyanide.-Place what remains of the first distillate in a casserole; add $\mathrm{I}-2 \mathrm{cc}$. $10 \% \mathrm{NaOH}$ solution, about $0.5 \mathrm{cc}$. I0\% $\mathrm{FeSO}_{4}$ solution (or about o. I g. solid $\mathrm{FeSO}_{4} \cdot 7 \mathrm{H}_{2} \mathrm{O}$ ), and I or 2 drops $10 \% \mathrm{FeCl}_{3}$ solution; and boil for one minute. To the hot mixture add $\mathrm{HCl}$ ( I. . 2) a few drops at a time until on shaking the dark colored precipitate of ferrous and ferric hydroxides is dissolved. Cool the mixture. If a precipitate is not plainly visible, filter, and wash out the filter paper once with water. (Blue precipitate, presence of cyanide.)

Notes. -1 . This test is based upon the formation of ferrocyanide by the action of cyanide on ferrous hydroxide and upon the reaction between this substance and the ferric salt whereby ferric ferrocyanide (Prussian blue) is formed, which is difficultly soluble in dilute hydrochloric acid.

2. A small precipitate is not readily detected in the hot reddish yellow solution, but is more easily seen in the cold light colored solution, especially after standing, or when collected on a filter. If the precipitate on the filter is not dark blue, it should be washed with a little hot, dilute hydrochloric acid. With these precautions, the test enables $0.2 \mathrm{mg} . \mathrm{CN}$ in the solution tested to be detected.

3. Cyanides may be present in the original substance in the form either of simple or of complex cyanides. The latter are characterized by complex anions (such as $\mathrm{Ag}(\mathrm{CN})_{2}^{-}$and $\mathrm{Fe}(\mathrm{CN})_{0}=$ ). These differ very greatly in their stability towards decomposing agents, the difference depending on the extent to which they are disso- 
ciated into the simple ions $\left(\mathrm{Ag}^{+}\right.$and $\mathrm{CN}^{-}$or $\mathrm{Fe}^{++}$and $\left.\mathrm{CN}^{-}\right)$. Ferrocyanides, ferricyanides, and cobalticyanides are so slightly dissociated in this way that scarcely any $\mathrm{HCN}$ is produced when dilute $\mathrm{HCl}, \mathrm{HNO}_{3}$, or $\mathrm{H}_{2} \mathrm{SO}_{4}$ is added to their cold solutions; but almost all the other complex cyanides (such as $\mathrm{KAg}(\mathrm{CN})_{2}$ or $\mathrm{K}_{2} \mathrm{Ni}(\mathrm{CN})_{4}$ ) are readily decomposed by these acids.

In the distillation with phosphoric acid (P. IOI), not only the simple cyanides, but also nearly all the complex cyanides are decomposed during the first part of the distillation; but a few very stable substances (such as Prussian blue) are completely decomposed only in the second part of the distillation. A further test for cyanide with a portion of the second distillate is therefore necessary when such complex cyanides may be present.

4. The following procedure enables $2 \mathrm{mg}$. cyanide to be detected in the presence of ferro or ferricyanide: Place in a $20 \mathrm{cc}$. distilling flask provided with a thistle tube $0.5^{-1}$ gram of the original substance, 2 grams powdered $\mathrm{CaCO}_{3}$, and to cc. water. Add very gradually through the thistle tube $2 \mathrm{cc}$. $\mathrm{HCl}$ (1.12), enough to decompose some, but not all of the $\mathrm{CaCO}_{3}$. Allow the gas which is evolved to pass into a small test tube containing $3 \mathrm{cc}$. $10 \% \mathrm{NaOH}$ and $3 \mathrm{cc}$. water. Finally heat the contents of the flask almost to boiling. Test the $\mathrm{NaOH}$ solution for cyanide by $\mathrm{P}$. 106 . This separation depends upon the fact that $\mathrm{HCN}$ is displaced by $\mathrm{H}_{2} \mathrm{CO}_{3}$ from simple cyanides and from the relatively unstable complex cyanides, such as $\mathrm{Ag}(\mathrm{CN})_{2}-$ or $\mathrm{Ni}(\mathrm{CN})_{4}=$, but not from ferro or ferricyanides.

5. Ferrocyanide and ferricyanide may be detected and distinguished from each other when only one of them is present, by adding a ferric salt to one portion of an aqueous or dilute acid solution, and by adding ferrous salt to another portion of the solution. A ferric salt gives a blue precipitate of ferric ferrocyanide with ferrocyanide, but no precipitate with a ferricyanide. A ferrous salt gives the same blue precipitate (of ferric ferrocyanide) with a ferricyanide; but it also gives with a ferrocyanide a precipitate (of ferrous ferrocyanide), which is white if no ferric salt is present, but which rapidly turns blue in contact with the air.

6. Ferrocyanide and ferricyanide may be detected in the presence of each other by proceeding as follows: Add to an aqueous or dilute solution of the substance $\mathrm{AgNO}_{3}$ and then a moderate excess of $\mathrm{NH}_{4} \mathrm{OH}$. (White precipitate insoluble in $\mathrm{NH}_{4} \mathrm{OH}$, presence of ferrocyanide. Orange to red precipitate readily soluble in $\mathrm{NH}_{4} \mathrm{OH}$, presence of ferricyanide.). Filter out and wash the precipitate, and pour over it a little $\mathrm{FeCl}_{3}$ solution. (Blue coloration, presence of ferrocyanide.) Acidify the ammoniacal filtrate with acetic acid, filter out' and wash the precipitate, and pour through the filter containing it a little FeS.O $\mathrm{O}_{4}$ solution (orange to red precipitate, which is turned blue by the $\mathrm{FeSO}_{4}$, presence of ferricyanide). This procedure enables $0.2 \mathrm{mg}$. $\mathrm{Fe}(\mathrm{CN})_{6}$ as either ferro or ferricyanide to be detected when present alone; but the test for ferricyanide is much less delicate in the presence of much ferrocyanide.

\section{Analysis of the Second and Third Distillates.}

Procedure 107.-Detection of Constituents Precipitable by Silver Nitrate. -To one-eighth of the second distillate add I cc. $\mathrm{HNO}_{3}$ ( I.20) and I cc. $4 \% \mathrm{AgNO}_{3}$ solution. (White precipitate, presence of chloride, cyanide, or thiocyanate; yellowish precipitate, presence of bromide or iodide; black precipitate, presence of sulfide; no precipitate, absence of all these in this distillate.)

If there is a precipitate, test separate eighths of the second distillate for sulfide by P. 105, for cyanide by P. 106 (see, however, Note 2), and for 
thiocyanate by P. I08; and then test the remainder for free halogen and halides by P. IOg and IIO, and for nitrate by P. III.

If there is no precipitate, test the distillate for nitrate by P. III.

Notes.-I. All the common silver salts, except the halides, cyanide, thiocyanate, and sulfide are either soluble in water (as are the nitrate, sulfate, chlorate, and fluoride) or dissolve readily in nitric acid owing to displacement of the weaker acid (as do the phosphate, carbonate, borate, and sulfite). It should be noted, however, that salts of weak acids are not necessarily readily soluble in a strong acid. Thus this is true of $\mathrm{Ag}_{2} \mathrm{~S}$ and $\mathrm{AgCN}$, which are precipitated from this distillate, if $\mathrm{H}_{2} \mathrm{~S}$ and $\mathrm{HCN}$ are present in it. Silver sulfide does not dissolve in dilute nitric acid because its solubility in pure water is so extremely small that there is only a very minute concentration of $\mathrm{S}^{=}$ion in the saturated solution, and this can yield, in accordance with the mass action law, only a relatively small concentration of $\mathrm{SH}^{-}$and unionized $\mathrm{H}_{2} \mathrm{~S}$ with the $\mathrm{H}^{+}$ion of the $\mathrm{HNO}_{3}$. Silver cyanide has for another reason a very slight concentration of its anion in its saturated solution, namely, owing to the fact that this salt exists in the solution mainly as $\mathrm{Ag}^{+}$and $\mathrm{Ag}(\mathrm{CN})_{2}^{-}$, and scarcely at all as $\mathrm{Ag}^{+}$and $\mathrm{CN}^{-}$

2. It is not necessary to test for sulfide and cyanide in this distillate when the original substance dissolved completely in the phosphoric acid during the first part of the distillation. When it does not so dissolve, $\mathrm{H}_{2} \mathrm{~S}$ and $\mathrm{HCN}$ (coming from complex cyanides) may be found wholly or in part in the second distillate.

Procedure ro8.-Detection of Thiocyanate.-If $\mathrm{AgNO}_{3}$ produced a precipitate (P. I07), dilute another eighth of the second distillate (P. IOI) to 5-IO cC., add 2-3 drops of a $10 \% \mathrm{FeCl}_{3}$ solution and 2-3 drops of $\mathrm{HCl}$ (I.I2). (Red color, presence of thiocyanate.)

Notes.-I. The red coloration arises from the formation by metathesis of $\mathrm{Fe}(\mathrm{SCN})_{3}$, a substance whose degree of ionization is relatively small. The $\mathrm{HCl}$ is added to reduce the hydrolysis of the $\mathrm{FeCl}_{3}$ and diminish the color imparted by it to the solution.

2. A distinct reddish yelfow coloration is produced by o.I $\mathrm{mg}$. SCN. A deep red color is obtained when I ing. or more is present.

3. Since in the distillation with phosphoric acid, thiocyanates are destroyed by certain oxidizing agents, such as nitrates, which do not act on it at ordinary temperatures, it is sometimes advisable to apply this test also to a solution of the original substance.

Procedure rog.-Detection and Removal of Free Halogens.-If $\mathrm{AgNO}_{3}$ gave a precipitate in $\mathrm{P}$. ${ }_{107}$, to two-thirds of the remainder of the second distillate in a separating funnel add $2-3 \mathrm{cc}$. chloroform and shake. (Purple color, presence of iodine; orange or yellow color, presence of bromine.)

If the chloroform is colorless, separate it from the aqueous layer. Add to the chloroform layer a few drops of $1 \% \mathrm{KI}$ solution. (Purple color, presence of chlorine, or of bromine in small quantity.) If there is no color, treat the aqueous layer left in the separating funnel by P. Iro.

If any free halogen is present, add to the mixture in the separating funnel ro cc. chloroform, shake, and separate the two layers. Repeat the extraction with a fresh Io cc. portion of chloroform. (Purple color of the chloroform layer and brown color of the aqueous layer, showing slow extraction of iodine, presence of iodide.) Test the aqueous layers for halides by P. I Io. 
If further tests for free bromine or chlorine are necessary, shake the chloroform extracts with IO cc. water, adding enough $\mathrm{H}_{2} \mathrm{SO}_{3}$ solution to reduce the halogen, and treat the aqueous layer by P. IIO.

Notes. $-r$. As to these tests see the notes to P. 103.

2. As there stated, the proportion of the iodine extracted from the aqueous layer by chloroform is much smaller when iodide is also present, so that some tri-iodide then remains in the aqueous solution after two extractions. Since this behavior itself shows the presence of iodide, it is not necessary to attempt to extract all the iodine before testing for halides by $P$. I 10 .

Procedure II0.-Detection of Halides.-Place the aqueous layer which is to be tested for halides (P. 1O9) in a separating funnel; add 3 cc. chloroform, 5 cc. $20 \%$ sodium acetate solution, 2 cc. $30 \%$ acetic acid, and I cc. $\mathrm{I} \% \mathrm{KMnO}_{4}$ solution (in excess of that required to oxidize any $\mathrm{H}_{2} \mathrm{SO}_{3}$ present), and shake. (Purple color, presence of iodide.) If there is a color, pour the mixture into a flask, add Io cc. more $\mathrm{CHCl}_{3}$, and then add gradually $1 \% \mathrm{KMnO}_{4}$ solution, shaking after each addition, till the aqueous layer becomes pink. Pour the mixture through a moistened filter to remove the chloroform and precipitated $\mathrm{MnO}_{2}$, and shake the filtrate once or twice with a fresh Io $\mathrm{cc}$. portion of chloroform to extract all the iodine.

Place the aqueous solution and $3 \mathrm{cc}$. chloroform in a separating funnel, add $5 \mathrm{cc} \mathrm{H}_{2} \mathrm{SO}_{4}$ (I.20), and I cc. $1 \% \mathrm{KMnO}_{4}$ solution, unless such an excess is already present, and shake. (Yellow or orange coloration of the chloroform, presence of bromide.)

Transfer the aqueous layer to a casserole, add 5-20 cc. I \% $\mathrm{KMnO}_{4}$ solution, and boil the mixture 3-5 minutes, or until the volume has been reduced to ro cc. "Filter off the $\mathrm{MnO}_{2}$, and, if the solution is still pink, add $\mathrm{H}_{2} \mathrm{SO}_{3}$ solution drop by drop until it is colorless. Dilute the solution to roo cc., filter if necessary, and add $2 \mathrm{cc} . \mathrm{HNO}_{3}(\mathrm{I}, 20)$ and $\mathrm{I}-2 \mathrm{cc}$. $4 \% \mathrm{AgNO}_{3}$ solution. (White precipitate, presence of chloride.)

Notes.-I. This separation is based upon the different rates at which $\mathrm{KMnO}$, sets free by oxidation the three halogens from their salts in a solution of definit hydrogenion $\left(\mathrm{H}^{+}\right)$concentration. A dilute solution of acetic acid containing considerable sodium acetate has such a hydrogen-ion concentration that an iodide is immediately oxidized by $\mathrm{KMnO}_{4}$ with liberation of iodine, while bromide and chloride are not oxidized to an appreciable extent in the time required for the operations. When the $\mathrm{H}^{+}$-concentration is increased by the addition of the prescribed quantity of $\mathrm{H}_{2} \mathrm{SO}_{4}$, the bromide is oxidized very rapidly while the rate of the corresponding reaction for the chloride is still so small at room temperature that scarcely any chlorine is set free. Even when the solution is boiled to expel the bromine, only a small fraction of the chloride present is oxidized to chlorine.

2. To secure satisfactory results, the directions as to the quantities of the acids added must be followed carefully. The proper quantity of $\mathrm{H}_{2} \mathrm{SO}_{4}$ is that required to react with all the sodium acetate, and in addition to give an excess equal to about I cc. $\mathrm{H}_{2} \mathrm{SO}_{4}$ (I.2O) per 20 cc. of solution.

3. A very small precipitate of $\mathrm{AgCl}$ obtained at the end of the procedu e does not necessarily indicate the presence of chloride in the substance, unless the reagents used have been proved to be entirely free from chloride. Even then a very slight precipitate 
(corresponding to less than $\mathrm{o.I} \mathrm{mg}$. $\mathrm{Cl}$ ) may result from a reaction between the permanganate and chloroform. For these reasons a blank test should be made in any doubtful case.

4. The yellow color of bromine in 3-5 cc. chloroform enables about $0.5 \mathrm{mg}$. Br to be detected in this procedure, which corresponds to $1-1.5 \mathrm{mg}$. $\mathrm{Br}$ in the whole of the second distillate. A much smaller quantity might be detected by separating the chloroform solution and adding KI solution to it; but when much chloride is present, this is an unreliable indication of bromide, since in that case an appreciable quantity of free chlorine may have been liberated by the permanganate. If it is desired to detect with certainty a smaller quantity of bromine, one may do so by treating the chloroform solution (obtained as described in the second paragraph of the above procedure), which contains the liberated bromine and perhaps a little chlorine, as follows: Shake it with $\mathrm{I}_{5} \mathrm{cc}$. water and $5 \mathrm{cc} . \mathrm{H}_{2} \mathrm{SO}_{4}$ (I.2O), to which a few drops of saturated $\mathrm{SO}_{2}$ solution are added; then add $1 \% \mathrm{KMnO}_{4}$ solution till the water layer becomes pink, and finally I cc. more. Shake well, separate the chloroform layer by means of a separating funnel, add to it a few drops KI solution, and shake again. A purple color shows the presence of bromide.

5. If $\mathrm{HCN}, \mathrm{H}_{2} \mathrm{~S}$, or $\mathrm{HSCN}$ are present in the distillate, they will be expelled or destroyed by the boiling with $\mathrm{KMnO}_{4}$ before the final test for chloride with $\mathrm{AgNO}_{3}$ is applied.

Procedure III.-Detection of Nitrate.-To the remainder of the second distillate (after removing any iodide or thiocyanate present by shaking with solid $\mathrm{Ag}_{2} \mathrm{SO}_{4}$ and filtering) add $3 \mathrm{cc} . \mathrm{H}_{2} \mathrm{SO}_{4}$ ( $\mathrm{I} .84$ ) and $5 \mathrm{cc}$. saturated $\mathrm{FeSO}_{4}$ solution. Place the mixture in the apparatus in P. IOI, and distil until only about $5 \mathrm{cc}$. remain, collecting the distillate in a mixture of $20 \mathrm{cc}$. water and $2 \mathrm{cc} .10 \% \mathrm{NaOH}$. Make the distillate acid with $\mathrm{H}_{2} \mathrm{SO}_{4}$, add 2-3 cc. chloroform and shake. If the chloroform is colorless, add a few drops of KI solution, and shake again. (Purple color, presence of nitrate.)

Notes.- - I. In this procedure the nitrate is reduced by the $\mathrm{FeSO}_{4}$ to nitric oxide (NO), which passes oter as a gas into the receiver, where it is oxidized by the oxygen of the air to $\mathrm{HNO}_{2}$, which is then absorbed by the NaOH. When the solution is acidified and $\mathrm{KI}$ added, $\mathrm{I}_{2}$ is liberated by the $\mathrm{HNO}_{2}$ (see P. IO3, N. 4). By this procedure 0.2 ing. $\mathrm{NO}_{8}$ in the liquid submitted to distillation can be detected.

2. The reaction is highly characteristic for nitrates, since any nitrous acid present passed over completely into the first distillate, and since other oxidizing substances (for example, chlorine or bromine) which might liberate iodine from potassium iodide are reduced by the $\mathrm{FeSO}$, to compounds which, even if they pass over into the distillate, have no action on KI. The only substances that may interfere are iodide and thiocyanate; and provision is therefore made for first removing these by adding solid $\mathrm{Ag}_{2} \mathrm{SO}_{4}$, shaking, and filtering.

Procedure Ir2.-Detection of Sulfate.-To the third distillate obtained upon heating with copper (P. IOI), add I-2 cc. $\mathrm{HCl}$ (I.I2), $5 \mathrm{cc} .2^{\circ} \%$ $\mathrm{BaCl}_{2}$ solution, and saturated $\mathrm{Br}_{2}$ solution till the liquid becomes yellow. (White precipitate, presence of sulfate.)

Notes.- $r$. By the action of copper in the presence of concentrated $\mathrm{H}_{3} \mathrm{PO}_{4}$ on sulfates (even the very difficultly soluble $\mathrm{BaSO}_{4}$ ) $\mathrm{SO}_{2}$ is formed. This is oxidized by the $\mathrm{Br}_{2}$ to $\mathrm{H}_{2} \mathrm{SO}_{4}$, which then precipitates as $\mathrm{BaSO}_{4}$. In this way I $\mathrm{mg}$. $\mathrm{SO}_{4}$ may be 
detected. Even when this small amount is present in the substance, only an inconsiderable proportion of it passes into the first and second distillates.

2. Much $\mathrm{H}_{3} \mathrm{PO}_{4}$ also passes over into the distillate; and the $\mathrm{HCl}$ is added to prevent its precipitation as $\mathrm{BaHPO}_{4}$. Too much $\mathrm{HCl}$ must not be added since $\mathrm{BaSO}_{4}$ is appreciably soluble in it.

3. When a sulfide is present which has not alteady been decomposed, sulfur and $\mathrm{H}_{2} \mathrm{~S}$ may pass into the third distillate, after the acid has become concentrated. The $\mathrm{H}_{2} \mathrm{~S}$ may be tested for in a portion of the distillate by $\mathrm{P}$. I05.

\section{Supplementary Procedures.}

Procedure Ir3.-Detection of Borate.-Place I-2 grams ${ }^{1}$ of the finely powdered substance in the distilling apparatus used in P. IOI, and add Io cc. of methyl alcohol $\left(\mathrm{CH}_{3} \mathrm{OH}\right)$ and two or three glass beads. Pour in carefully 3 cc. $\mathrm{H}_{2} \mathrm{SO}_{4}(\mathbf{I} .84)$, and distil off the alcohol, collecting it in a mixture of $5 \mathrm{cc} . \mathrm{CH}_{3} \mathrm{OH}$ and $3 \mathrm{cc} . \mathrm{HCl}$ (I.2O). Make the distillate up to I 8 cc. with $\mathrm{CH}_{3} \mathrm{OH}$, cool, and add five drops of a saturated solution of turmeric in ethyl alcohol. (Red or orange color, presence of borate.) To estimate roughly the quantity present, compare the color with that given by adding the turmeric solution to known quantities of borate dissolved in a mixture of 3 ce. $\mathrm{HCl}$ ( $\mathrm{I} .2 \mathrm{O}$ ) and $\mathrm{I}_{5} \mathrm{cc}$. $\mathrm{CH}_{3} \mathrm{OH}$.

Notes.-I. Methyl alcohol reacts with boric acid to form its methyl ester $\mathrm{B}\left(\mathrm{OCH}_{3}\right)_{3}$, which is a readily volatil liquid. The color given by turmeric to a solution of this ester in methyl alcohol and strong hydrochloric acid is so intense that the test is very delicate if the proportions given are reproduced. The presence of $\mathrm{I} \mathrm{mg} . \mathrm{BO}_{2}$ in the strbstance distilled may readily be detected.

2. If the substance be distilled with $\mathrm{H}_{2} \mathrm{SO}_{4}$ and ethyl alcohol (instead of methyl alcohol), much less borate passes into the distillate, and the test is much less delicate.

Procedure II4.-Detection of Fluoride.-Mix $0.2 \mathrm{~g}$. of the dry, finely powdered substance with twice its weight of powdered $\mathrm{KHSO}_{4}$ and with IO-20 mg. dry, finely powdered or precipitated $\mathrm{SiO}_{2}$. Blow a thickwalled bulb $\mathrm{I} / 2-2 \mathrm{~cm}$. in diameter at the end of a glass tube of $5-8 \mathrm{~mm}$. bore. Place the mixture in the bulb (not using more of it than will onethird fill the bulb). Heat the bulb carefully until the $\mathrm{KHSO}_{4}$ is melted, taking care that the mixture does not froth up into the tube. Continue to heat the bulb and the lower part of the tube until there is a deposit of a solid substance or of condensed acid 3 or $4 \mathrm{~cm}$. above the bulb. After it has cooled, cut off the tube close to the bulb. Dip the tube several times in water, dry it in a flame, and heat it strongly. (White deposit in the middle part of the tube and etched surface at the lower end, presence of fuoride.)

Notes.-1. This test depends on the following reactions:

$$
\begin{aligned}
& { }_{4} \mathrm{HF}+\mathrm{SiO}_{2}=\mathrm{SiF}_{4}+2 \mathrm{H}_{2} \mathrm{O} \\
& 3 \mathrm{SiF}_{4}+{ }_{3} \mathrm{H}_{2} \mathrm{O}=\mathrm{H}_{2} \mathrm{SiO}_{3}+2 \mathrm{H}_{2} \mathrm{SiF}_{6} .
\end{aligned}
$$

${ }^{1}$ In this procedure and the subsequent ones, it is directed to take such an amount of substance as will enable $0.1-0.2 \%$ of the acidic constituent in question to be detected. The amount taken may of course be varied in accordance with the nature of the material and the object in view. 
Some of the $\mathrm{HF}$ liberated by the molten $\mathrm{KHSO}_{4}$ volatilizes and takes the silica required for the first reaction from the glass, thus producing the characteristic etched surface in the lower part of the tube. The $\mathrm{SiF}_{4}$ gas and the water vapor liberated react in the cooler part of the tube according to the second equation, forming a white ring of solid silicic and fluosilicic acids in the tube. The reaction is reversed at higher temperatures, so that the deposit may be driven up the tube by heating. This white deposit is the most characteristic part of the test for fluoride, since in the subsequent washing $\mathrm{H}_{2} \mathrm{SiF}_{6}$ is removed and there remains $\mathrm{H}_{2} \mathrm{SiO}_{3}$ alone, which is converted into $\mathrm{SiO}_{2}$ on heating. A deposit of $\mathrm{SO}_{2}$ and $\mathrm{H}_{2} \mathrm{SO}_{4}$ may also form in the upper part of the tube, and might be mistaken for, or interfere with, the test for small amounts of fluoride, if the final washing with water is omitted. This procedure enables $0.5 \mathrm{mg}$. $\mathrm{F}$ to be easily detected.

2. The test fails with certain minerals which are not decomposed by fusion with $\mathrm{KHSO}_{4}$; but such cases are provided for by the treatment described in P. II6.

3. Fluoride is often tested for by heating the solid substance in a platinum crucible with $\mathrm{H}_{2} \mathrm{SO}_{4}$ alone, and detecting any $\mathrm{HF}$ involved by its etching action on a watch glass coated with wax through which markings have been made. This test has the disadvantage that in the presence of silica or silicate, which is very often present in minerals, it is unreliable owing to the conversion of the $\mathrm{HF}$ to $\mathrm{SiF}_{4}$ by the reaction given in note $I$.

4. In distilling a fluoride with $\mathrm{H}_{3} \mathrm{PO}_{4}$ by $\mathrm{P}$. IOI, much of the $\mathrm{HF}$ reacts with the glass, but enough of it passes into the second distillate to enable $2-3 \mathrm{mg}$. $\mathrm{F}$ in the substance to be detected, if the whole distillate be tested with $\mathrm{NaC}_{2} \mathrm{H}_{3} \mathrm{O}_{2}$ and $\mathrm{CaCl}_{2}$ as described in P. II6.

5. The precipitation of $\mathrm{CaF}_{2}$ in an acetic acid solution from any source distinguishes fluoride from all the other acidic constituents except sulfate and oxalate, and is delicate enough to enable $0.2 \mathrm{mg}$. $\mathrm{F}$ in Io $\mathrm{cc}$. solution to be detected. The presence of fluoride in such a precipitate, even in a small one, can be confirmed by drying it, mixing it with a little $\mathrm{KHSO}_{4}$ and $\mathrm{SiO}_{2}$, and heating as described in the procedure.

Procedure Ir5.-Detection of Phosphate.-To $0 . \mathrm{I}-0.2 \mathrm{~g}$. of the finely powdered substance add about $5 \mathrm{cc} . \mathrm{HNO}_{3}(\mathrm{I}, 2 \mathrm{O})$. If the substance does not dissolve, boil the mixture for 2 or 3 minutes, and filter. Add to the filtrate an equal volume of $\left(\mathrm{NH}_{4}\right)_{2} \mathrm{MoO}_{4}$ solution, and allow it to stand 5 to ro minutes. (Yellow precipitate, presence of phosphate.)

Notes.-I. The yellow precipitate produced is a complex compound, ammonium phosphomolybdate, of a composition varying somewhat with the conditions, but approximating that represented by the formula $\left(\mathrm{NH}_{4}\right)_{3} \mathrm{PO}_{4}$. $12 \mathrm{MoO}_{3}$.

2. In order that the test may be delicate; a large proportion of the $\left(\mathrm{NH}_{4}\right)_{2} \mathrm{MoO}_{4}$ must be present to reduce the solubility of the precipitate; and a short time must be allowed for the formation of the complex phosphomolybdate. This is promoted by gentle warming; but in a hot solution arsenate or silicate may give rise to a similar yellow precipitate, while in the cold the reaction is given only by phosphate. By this test 0.1 mg. $\mathrm{PO}_{4}$ may be easily detected. The great delicacy of this test should be borne in mind in estimating the quantity of phosphate present.

3. Phosphate will have been detected in Part III (P. 63) of this system of analysis when elements of the iron, aluminum, or calcium groups are present.

Procedure II6.-Detection of the Acidic Constituents in Undecomposed Substances. - If the substance is not completely decomposed by acids (as shown in $\mathrm{P}$. Ior and I I 5) heat I $\mathrm{g}$. of the finely powdered substance with 
$\mathrm{HNO}_{3}$ (I. 20), filter out and wash the residue, dry it, separate from the filter, and mix it with $5^{-1 O}$ g. dry $\mathrm{Na}_{2} \mathrm{CO}_{3}$ in a platinum crucible (or in a porcelain crucible, if reducible metals may be present in it): Cover the crucible and heat it over a powerful burner for 5-10 minutes. If a perfectly clear fusion does not result, add more $\mathrm{Na}_{2} \mathrm{CO}_{3}$, and heat again over a blast lamp. Cool, place the crucible in a casserole, boil it with water till the fused mass is disintegrated, and filter, rejecting the residue.

To a portion of the filtrate add $\mathrm{HNO}_{3}$ (I.20) till it is distinctly acid, and test portions of it for chloride by adding $\mathrm{AgNO}_{3}$, for phosphate by P. II5, and for sulfate by adding $\mathrm{BaCl}_{2}$ solution.

Test another portion of the filtrate for borate by evaporating it to complete dryness, adding $\mathrm{H}_{2} \mathrm{SO}_{4}$ ( $\mathrm{I}, 84$ ) drop by drop, and treating the mixture by P. I 3 .

Test a third portion of the filtrate for fluoride as follows: add $5 \mathrm{cc}$. $20 \% \mathrm{NaC}_{2} \mathrm{H}_{3} \mathrm{O}_{2}$ solution and $5 \mathrm{cc}, 10 \% \mathrm{CaCl}_{2}$ solution, allow the mixture to stand Io-1 5 minutes. (White precipitate, presence of fuoride.) To confirm its presence, filter out, wash, and dry the precipitate, and test it by P. II 4 .

If silicate needs to be tested for, evaporate a portion of the solution, heat the residue at $100-125^{\circ}$ till it is perfectly dry, add $\mathrm{HCl}$ (I.20) and boil gently. (White residue, presence of silicate or silica.) To confirm its presence, treat the residue by P. 5 (Part I).

Notes.- $\mathrm{I}$. Fusion with $\mathrm{Na}_{2} \mathrm{CO}_{3}$ metathesizes nearly all insoluble compounds in the way described in the notes to P. 8 (Part I of this System of Analysis).

2. If basic elements that may be reduced to the metallic state (those of the silver, copper, and tin groups) nay be present in the insoluble residue, it must be fused in a porcelain instead of a platinum crucible. It is, however, less desirable to use a porcelain crucible, since it is more difficult to attain the high temperature necessary, and since it is attacked by the flux and silicate is thereby introduced into the solution.

3. In minerals or metallurgical products undecomposed by acids, it is usually necessary to test only for silicate, chloride, sulfate, phosphate, borate, and fluoride, since other acidic constituents are scarcely ever present.

4. In a substance undecomposed by acids the presence of halides, sulfide, or sulfate can also be detected by proceeding as follows: Place about 0 . Io $\mathrm{g}$. of the solid substance in an iron tube about $15 \mathrm{~cm}$. 'long and $1.5 \mathrm{~cm}$. in outside diameter, or in a Jena glass tube, heat for $2-3$ minutes to drive off water and to deconipose unstable substances, cool and add roo mg. freshly cut sodium. Heat the mixture strongly under a hood for 2-3 minutes, and allow to cool. Add I cc. methyl alcohol and after several minutes a little water, drop by drop. Then add $5 \mathrm{cc}$. water, shake and filter into a test tube. Acidify with acetic acid, and treat I-2 cc. with $\mathrm{AgNO}_{3}$ and $\mathrm{HNO}_{3}$ (P. 107). If there is a precipitate, test one-third of the acetic acid solution for sulfide by adding $2 \mathrm{cc}$. $10 \% \mathrm{Cd}\left(\mathrm{NO}_{3}\right)_{2}$ solution (P. ${ }_{105}$ ), and test the remainder for iodide, bromide, and chloride by $\mathrm{P}$. I 1 .

Compounds containing sulfur, even such stable substances as $\mathrm{BaSO}_{4}, \mathrm{MoS}_{2}, \mathrm{CuS}$, are decomposed by this process with formation of sodium sulfide, and compounds containing chlorine, bromine, or iodine, even $\mathrm{AgBr}$ and $\mathrm{AgI}$, are decomposed with formation of sodium balide. In the case of a substance of entirely unknown character, 
only a small quantity (10-20 mg.) should be used at first, as the reaction with sodium might be a very violent one.

Procedure II7.-Detection of Hypochlorite.-To about $0.5 \mathrm{~g}$. of the powdered substance mixed with $5 \mathrm{cc}$. water, or to $5 \mathrm{cc}$. of the alkalin solution, add acetic acid, a few drops at a time, until the solution is acid. Filter if there is much residue, add $2 \mathrm{cc}$. $20 \%$ lead acetate solution, heat the mixture to boiling, and let it stand for ten minutes. (Brown precipitate, presence of hypochlorite.)

Notes.-r. Hypochlorites are commonly met with either in alkalin solution or in the form of a powder (for example, in bleaching powder). Since they are prepared by the action of chlorine on alkali, chloride is ordinarily present in nearly equivalent amount. When the solid powder is treated with water, the hypochlorite passes into solution; and from it the unionized $\mathrm{HClO}$ is liberated upon the addition of the more largely ionized acetic acid. Chlorine is also formed until the equilibrium-conditions of the reaction $\mathrm{HClO}+\mathrm{Cl}^{-}+\mathrm{H}^{+}=\mathrm{Cl}_{2}+\mathrm{H}_{2} \mathrm{O}$ are satisfied. When in neutralizing with acetic acid litmus paper is used, the paper will soon be bleached if hypochlorite is present; but the color at the first instant or on the edges of the bleached portion can usually be observed.

2. This test depends upon the oxidation of the lead salt to lead dioxide $\mathrm{PbO}_{2}$ by the hypochlorite. The reaction takes place so slowly in the cold that not less than ro $\mathrm{mg}$. $\mathrm{ClO}$ in $5 \mathrm{cc}$. solution can be detected at room temperature, even if the mixture be allowed to stand a few minutes. But when the mixture is heated the limit of detectability is about $0.5 \mathrm{mg}$. in $5 \mathrm{cc}$. Since oxidation does not take place in the presence of a strong acid, such as $\mathrm{HNO}_{3}$, acetic acid is used in acidifying the solution.

3. Peroxides in alkalin solution react instantaneously with lead salts, forming $\mathrm{PbO}_{2}$; but this reaction does not take place in the presence of acetic acid, even on boiling. Therefore in the above procedure a peroxide will not be mistaken for a hypochlorite. Peroxide and hypochlorite, moreover, cannot exist together, since they react very rapidly with formation of oxygen. If desired, peroxide may be, tested for by treating the substance with a dilute acid and adding a few drops of a titanium sulfate solution (see P. 65 ) ).

4. This test for hypochlorite may be made even more delicately in alkalin solution, provided peroxides are known to be absent. If the solution is only slightly alkalin, a small white precipitate of $\mathrm{Pb}(\mathrm{OH})_{2}$ or $\mathrm{PbCO}_{3}$ is first formed; but this turns brown if hypochlorite is present when the mixture is heated and allowed to stand. The delicacy is of course diminished by the presence of large amounts of $\mathrm{Pb}\left(\mathrm{OH}_{2}\right)$ or $\mathrm{PbCO}_{3}$; but $\mathrm{I} \mathrm{mg}$. ClO can be detected in the presence of even 2 or 3 grams of these substances, provided an excess of the lead salt is still present in the solution, and the mixture is boiled vigorously, preferably in a casserole.

5. Hypobromite in alkalin solution or bromine in acetic acid solution also oxidizes lead salts to $\mathrm{PbO}_{2}$. Hypobromite is, however, so unstable that it will not be met with except in a solution freshly prepared from bromine and alkali. The results of previous tests will usually show whether $\mathrm{HClO}$ or $\mathrm{Br}_{2}$ has given rise to the $\mathrm{PbO}_{2}$ precipitate. In a doubtful case the halogens may be extracted by chloroform from an acid solution, and tested for by P. IOg and I 10 . On account of the equilibrium referred to in note I chlorine will be extracted in large proportion only if a strong acid or if much chloride is present.

Procedure II8.-Detection of Chlorate.-If chlorine has been found present in the first or second $\mathrm{H}_{3} \mathrm{PO}_{4}$ distillate, treat $0.5 \mathrm{~g}$. of the sub- 
stance in the cold with $50 \mathrm{cc}$. water and ro cc. $\mathrm{HNO}_{3}$ (I. 20). (If hypochlorite is present as shown by $\mathrm{P}$. II 7 , reduce it by adding $\mathrm{Na}_{3} \mathrm{AsO}_{3}$ solution in excess.) Add $4 \% \mathrm{AgNO}_{3}$ solution as long as a precipitate forms and then about $5 \mathrm{cc}$. more. Shake the mixture and filter off the precipitate. To the filtrate add $5 \mathrm{cc}$. saturated $\mathrm{SO}_{2}$ solution, heat the mixture or allow it to stand five minutes. (White precipitate, presence of chlorate (or bromate).)

Notes. - I. In this procedure chlorate is reduced to chloride by the $\mathrm{H}_{2} \mathrm{SO}_{3}$. The reaction is not instantaneous; but it is so rapid in the presence of a large excess of $\mathrm{H}_{2} \mathrm{SO}_{3}$ that at room temperature I $\mathrm{mg}$. $\mathrm{ClO}_{3}$ gives a distinct precipitate of $\mathrm{AgCl}$ within 5 minutes, even in a volume of roo cc.

2. If iodate is present, it is precipitated upon the first addition of $\mathrm{AgNO}_{3}$, along with the silver halides; but if bromate is present, some of it remains in the solution and shows the same behavior as chlorate. If necessary to distinguish between them, the final precipitate with $\mathrm{AgNO}_{3}$ may be treated as follows: Suspend it in $25 \mathrm{cc}$. water, pass in $\mathrm{H}_{2} \mathrm{~S}$ until the mixture is saturated with it, heat to boiling, filter off the precipitated $\mathrm{Ag}_{2} \mathrm{~S}$, boil the filtrate till the $\mathrm{H}_{2} \mathrm{~S}$ is expelled, and test it for bromide and chloride by P. I Io.

Procedure Ir9.-Detection of Sulfite and Thiosulfate.-If in P. IO2 the first distillate was found to contain $\mathrm{H}_{2} \mathrm{SO}_{3}$, add 0.5 gram of the finely powdered original substance to $5 \mathrm{cc}$. water and $\mathrm{I}-5 \mathrm{cc}$. $10 \% \mathrm{Na}_{2} \mathrm{CO}_{3}$ solution, shake the mixture, filter out any precipitate or residue, and add to the solution $3 \mathrm{cc}$. $10 \% \mathrm{Sr}\left(\mathrm{NO}_{3}\right)_{2}$ solution, then at once add slowly $30 \%$ acetic acid, at the last a few drops at a time, until the precipitate of $\mathrm{SrCO}_{3}$ dissolves on shaking, or until the solution reacts acid to litmus. Heat the mixture to boiling, add a drop or two of acetic acid if a flocculent precipitate forms, and let the mixture stand 15 minutes. (No precipitate, absence of sulfite.)

Filter out the $\operatorname{Sr}\left(\mathrm{NO}_{3}\right)_{2}$ precipitate, wash it once with a little cold water, pour a portion of $3-5 \mathrm{cc} . \mathrm{HCl}(\mathrm{I} .06)$ two or three times through the filter, and add to the solution $5 \mathrm{cc}$. $\mathrm{BaCl}_{2}$ solution. (If a precipitate of $\mathrm{BaSO}_{4}$ forms, filter it out.) Then add to the solution saturated $\mathrm{Br}_{2}$ solution till the liquid is slightly yellow. (Precipitate, presence of sulfite.)

To the filtrate from the $\mathrm{Sr}\left(\mathrm{NO}_{3}\right)_{2}$ precipitate, add I-2 cc. $\mathrm{HCl}$ (I.20), heat the mixture to boiling, and let it stand overnight. (White turbidity or yellow precipitate, presence of thiosulfate.)

Notes.- $\mathrm{I} . \mathrm{Na}_{2} \mathrm{CO}_{3}$ is added at the beginning of this procedure to separate from the acidic constituents in question any basic constituents present that may be precipitable by it. Its addition and the subsequent neutralization of it by acetic acid also serve to give a solution of small $\mathrm{H}^{+}$concentration, which is essential for a satisfactory separation of sulfite and thiosulfate. When the $\mathrm{H}^{+}$concentration is large, $\mathrm{SrSO}_{3}$ dissolves and the thiosulfate decomposes with formation of sulfur; but in acetic acid solution the latter reaction is negligible even on heating in the presence of a considerable excess of the acid. $\mathrm{SrSO}_{3}$ separates as a crystallin precipitate, slowly in the cold when present in small quantity, but much more rapidly when the mixture is heated. This procedure enables $\mathrm{Img} . \mathrm{SO}_{3}$ in an initial volume of $\mathrm{IO} \mathrm{cc}$, to be easily detected. 
2. Upon the addition of a moderate excess of $\mathrm{HCl}$ over that required to react with all the sodium acetate present, the thiosulfate decomposes with the separation of sulfur. When Io $c c$. of solution are treated by the above procedure, a precipitate of $\mathrm{S}$ forms within 30 minutes with $3 \mathrm{mg} . \mathrm{S}_{2} \mathrm{O}_{3}$, and on standing over night with $\mathrm{I} \mathrm{mg}$. $\mathrm{S}_{2} \mathrm{O}_{3}$.

\section{Confirmatory Experiments.}

P. IOI-II2. Test Analysis.-A mixture of $2 \mathrm{mg}$. of each of the constituents $\mathrm{CN}, \mathrm{Cl}, \mathrm{Br}, \mathrm{I}, \mathrm{NO}_{3}, \mathrm{SO}_{4}, \mathrm{SO}_{3}, \mathrm{CO}_{3}$, as the sodium or potassium salt, was dissolved in $2 \mathrm{c}$. water and tested according to $P$. IOI-II2: distinct and satisfactory tests were obtained for each constituent.

P. IOI. Distillation with Phosphoric Acid.-The experiments tabulated below were carried out to determin the behavior of the various acidic constituents in the phosphoric acid distillation. The division into first and second distillates corresponds to that given in P. IOI. The substances taken are given in the first column, the substances tested for in the distillates are given in the second column, and the results of the tests are given in the third and fourth columns. The numbers in the last two columns show the amount of substance estimated to be present in the distillates. The letter $\mathrm{S}$ denotes that the test was satisfactory, and that the amount of substance found seemed to correspond to that taken.

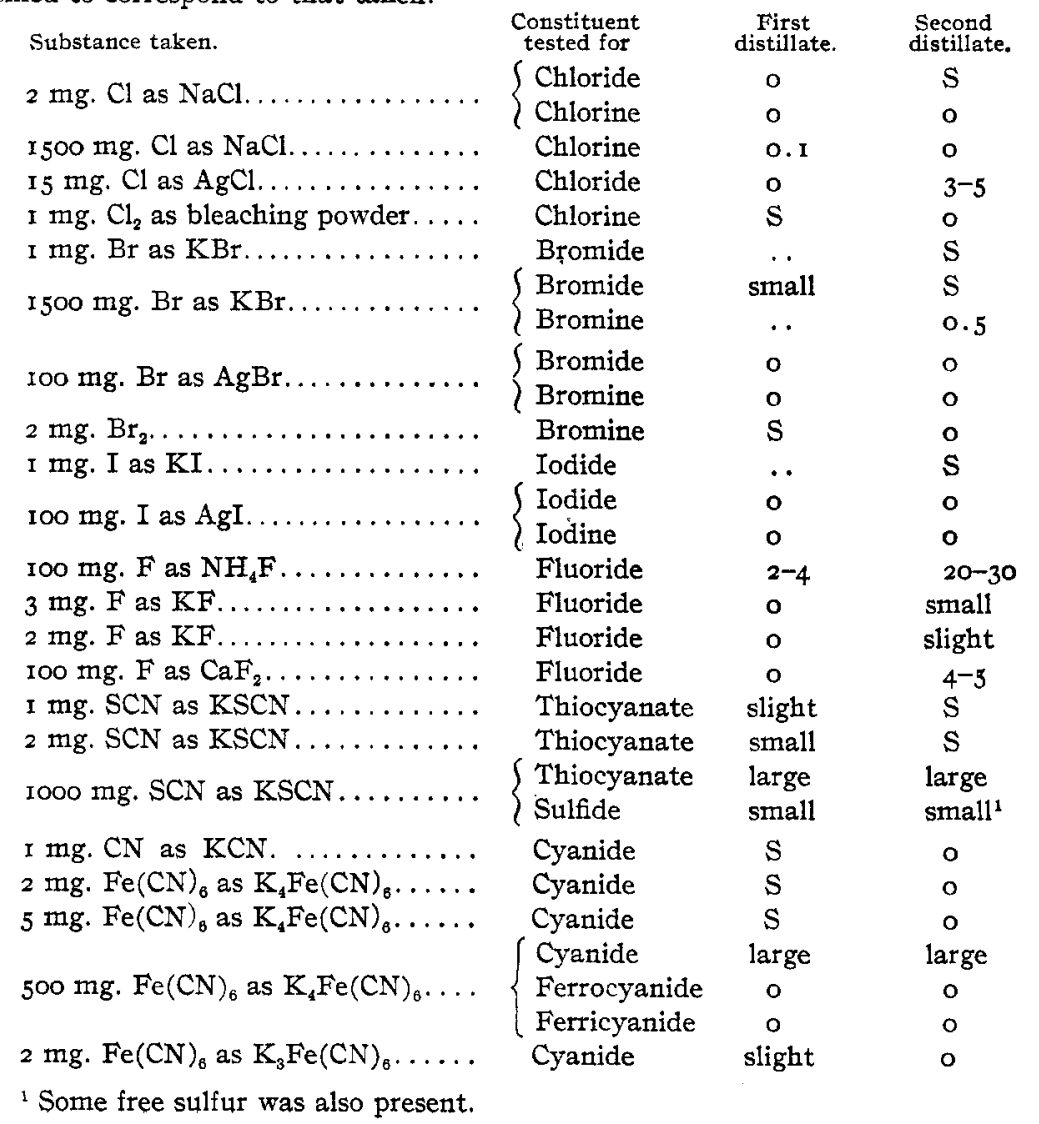




\begin{tabular}{|c|c|c|c|}
\hline Substarice taken. & $\begin{array}{l}\text { Constituent } \\
\text { tested for }\end{array}$ & $\begin{array}{c}\text { First } \\
\text { distillate. }\end{array}$ & $\begin{array}{l}\text { Second } \\
\text { distillate }\end{array}$ \\
\hline $5 \mathrm{mg} . \mathrm{Fe}(\mathrm{CN})_{0}$ as $\mathrm{K}_{8} \mathrm{Fe}(\mathrm{CN})_{6} \ldots \ldots$ & $\begin{array}{l}\text { Cyanide } \\
\text { Cyanide }\end{array}$ & $\begin{array}{l}\text { small } \\
\text { large }\end{array}$ & $\stackrel{o}{\text { large }}$ \\
\hline $600 \mathrm{mg} . \mathrm{Fe}(\mathrm{CN})_{6}$ as $\mathrm{K}_{3} \mathrm{Fe}(\mathrm{CN})_{\theta} \ldots$ & $\begin{array}{l}\text { Ferrocyanide } \\
\text { Ferricyanide }\end{array}$ & 0 & $\begin{array}{l}0 \\
0\end{array}$ \\
\hline 700 mg. Prussian blue.. & Cyanide & large & large \\
\hline $100 \mathrm{mg} . \mathrm{S}$ as CuS. ....... & Sulfide & o & trace ${ }^{1}$ \\
\hline 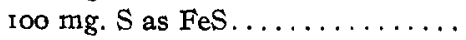 & Sulfide & large & small \\
\hline $900 \mathrm{mg}$. galena . . . . . . . . . . & Sulfide & large & large \\
\hline $700 \mathrm{mg}$. pyrite $\ldots \ldots \ldots \ldots \ldots \ldots$ & Sulfide & o & large ${ }^{1}$ \\
\hline $710 \mathrm{mg} . \mathrm{MoS}_{2} \ldots \ldots \ldots \ldots \ldots \ldots \ldots$ & Sulfide & $\mathbf{o}$ & o \\
\hline I mg. $\mathrm{NO}_{2}$ as $\mathrm{NaNO}_{2} \ldots \ldots \ldots \ldots$ & Nitrite & S & .. \\
\hline $20 \mathrm{mg} . \mathrm{NO}_{2}$ as $\mathrm{NaNO}_{2} \ldots \ldots \ldots \ldots$ & Nitrite & $\mathbf{S}$ & $\cdots$ \\
\hline I mg. $\mathrm{SO}_{3}$ as $\mathrm{Na}_{2} \mathrm{SO}_{3} \ldots \ldots \ldots \ldots \ldots$ & Sulfite & doubtful & o \\
\hline $2 \mathrm{mg} \cdot \mathrm{SO}_{8}$ as $\mathrm{Na}_{2} \mathrm{SO}_{3} \ldots \ldots \ldots$ & Sulfite & $\mathbf{S}$ & o \\
\hline $20 \mathrm{mg} . \mathrm{SO}_{3}$ as $\mathrm{Na}_{2} \mathrm{SO}_{3} \ldots \ldots \ldots$ & Sulfite & S & o \\
\hline $400 \mathrm{mg} \cdot \mathrm{C}_{2} \mathrm{O}_{4}$ as $\left(\mathrm{NH}_{4}\right)_{2} \mathrm{C}_{2} \mathrm{O}_{4} \ldots \ldots$ & Carbonate & o & large \\
\hline $5 \mathrm{mg} \cdot \mathrm{ClO}_{3}$ as $\mathrm{KClO}_{3}$. & $\left\{\begin{array}{l}\text { Chloride } \\
\text { Chlorine }\end{array}\right.$ & $\begin{array}{l}\circ \\
\text { slight }\end{array}$ & $\begin{array}{l}\text { slight } \\
0\end{array}$ \\
\hline I $500 \mathrm{mg} . \mathrm{ClO}_{3}$ as $\mathrm{KClO}_{3}$. & $\left\{\begin{array}{l}\text { Chloride } \\
\text { Chlorine }\end{array}\right.$ & $\begin{array}{l}\circ \\
\text { slight }\end{array}$ & $\begin{array}{l}\text { large } \\
\text { large }\end{array}$ \\
\hline $45 \mathrm{mg} . \mathrm{BrO}_{3}$ as $\mathrm{KBrO}_{3}$. & $\left\{\begin{array}{l}\text { Bromide } \\
\text { Bromine }\end{array}\right.$ & $\begin{array}{l}\text { large } \\
\text { large }\end{array}$ & $\begin{array}{l}\text { large } \\
\text { large }\end{array}$ \\
\hline $50 \mathrm{mg} \cdot \mathrm{S}_{2} \mathrm{O}_{3}$ as $\mathrm{Na}_{2} \mathrm{~S}_{2} \mathrm{O}_{3}$ & $\left\{\begin{array}{l}\text { Sulfide } \\
\text { Sulfur }\end{array}\right.$ & $\begin{array}{l}\text { large } \\
\text { small }\end{array}$ & $\begin{array}{l}\text { small } \\
\text { small }\end{array}$ \\
\hline $2 \mathrm{mg} . \mathrm{S}_{2} \mathrm{O}_{3}$ as $\mathrm{Na}_{2} \mathrm{~S}_{2} \mathrm{O}_{3}$. & Sulfide & $\mathbf{S}$ & . \\
\hline
\end{tabular}

P. IoI, N. 4. Detecti.n of Carbonate--Several experiments were made in which the first distillate was collected in a weakly ammoniacal solution. It was found that the addition of $\mathrm{Ba}(\mathrm{OH})_{2}$ often failed to precipitate small amounts of carbonate, especially when the $\mathrm{NH}_{4} \mathrm{OH}$ had been first neutralized with acetic acid.

P. IOI, N. 5 and 9. Action of Phosphoric Acid and Copper on Sulfates.-100 mg. $\mathrm{SO}_{4}$ as $\mathrm{Na}_{2} \mathrm{SO}_{4}$ were placed in a distilling flask together with ro cc. of $\mathrm{H}_{3} \mathrm{PO}_{4}$ and 3-4 grams of fresh $\mathrm{Cu}$ turnings, and the mixture was boiled down to the point where faint fumes were first seen: the distillate was found to contain neither $\mathrm{H}_{2} \mathrm{SO}_{3}$ nor $\mathrm{H}_{2} \mathrm{SO}$. The distillation was then continued 3 to 5 minutes longer and the vapors collected in water: the distillate now smelled strongly of $\mathrm{SO}_{2}$ and on adding $\mathrm{HCl}, \mathrm{Br}_{2}$, and $\mathrm{BaCl}_{2}$ (P. II2) a large precipitate was obtained. This experiment was repeated with I ing. $\mathrm{SO}_{4}$, except that the distillate was collected in a dilute $\mathrm{NaOH}$ solution: a precipitate of $\mathrm{BaSO}_{4}$ was obtained in $\mathrm{P}$. II2, which was estimated to be equivalent to the $\mathrm{SO}_{4}$ taken. The experiment was repeated with no sulfate: a satisfactory blank test rcsulted. The experiment was repeated with $125 \mathrm{mg}$. and with $2 \mathrm{nig}$. $\mathrm{SO}_{4}$ as precipitated $\mathrm{BaSO}_{4}$, the vapors being collected in water; the $\mathrm{BaSO}_{4}$ precipitates in P. I I 2 were estimated to contain $20 \mathrm{mg}$. and $2 \mathrm{mg}$. $\mathrm{SO}_{4}$, respectively.

P. IоI, N. 8. Absorption of Carbon Dioxide from the Air.- Io cc. $\mathrm{H}_{3} \mathrm{PO}_{4}$ were added to $25 \mathrm{cc}$. Water, the mixture was placed in the distilling flask and boiled $2-3$ minutes, the distillate being collected in nearly saturated solution of $\mathrm{Ba}(\mathrm{OH})_{2}$ contained in a roo cc. flask fitted with a two hole stopper: a small but distinct precipitate was obtained, becoming larger on cooling. The outlet hole of the receiving flask was fitted with a small soda-lime tube and the distillation repeated: a small precipitate was again

' Some free sulfur was also present. 
obtained. Io cc. $\mathrm{H}_{3} \mathrm{PO}_{4}$ were mixed with $20 \mathrm{cc}$. water, the mixture was brought to boiling and was then added through the upright safety tube to the distilling apparatus to which the receiving $\mathrm{Ba}(\mathrm{OH})_{2}$ flask had previously been attached: on distilling a few minutes only a very slight turbidity appeared in the $\mathrm{Ba}(\mathrm{OH})_{2}$ solution.

P. I0I, N. 7. Separation of Carbonate and Sulfite.-Three I5 cc. samples, containing $3 \mathrm{mg} . \mathrm{SO}_{3}$ and $\mathrm{O}, \mathrm{I}$, and $2 \mathrm{mg} . \mathrm{CO}_{3}$, respectively, were treated with $3 \mathrm{cc}$. of a saturated $\mathrm{Ba}(\mathrm{OH})_{2}$ solution acidified with $\mathrm{HC}_{2} \mathrm{H}_{3} \mathrm{O}_{2}$, with I cc. $\mathrm{HCl}$ (I.I2), and with bromine water till distinctly yellow. The different samples were then distilled into a $\mathrm{Ba}(\mathrm{OH})_{2}$ solution. The first gave a slight turbidity, the second a pronounced tur. bidity, and the third a distinct precipitate of $\mathrm{BaCO}_{3}$.

Several attempts were made to effect the separation of sulfite from carbonate by filtering out $\mathrm{BaSO}_{3}$ from an acetic acid solution of the carbonate. It was not found possible to prevent the finely divided sulfite from passing through the filter.

P. I03, N. 2. Distribution Ratios.-Approximate values of the distribution ratio of jodine and bromine at $25^{\circ}$ between certain organic solvents and water are given in the following table:

\begin{tabular}{|c|c|c|}
\hline & $\mathrm{CCl}_{3}$. & $\mathrm{CHBr}_{3}$. \\
\hline $10 n$ ratio i & 85 & 450 \\
\hline
\end{tabular}

Jakowkin's data ${ }^{1}$ show that the change with the concentration of the halogen is small. From the solubility determinations of Bruner, ${ }^{2}$ it seems probable that the distribution ratios for $\mathrm{CHCl}_{3}$ lie between those for $\mathrm{CCl}_{4}$ and $\mathrm{CHBr}_{3} \cdot{ }^{3}$

5: According to Jakowkin, the distribution ratio of the molecular species $\mathrm{Cl}_{2}$ between $\mathrm{CCl}_{4}$ and water is 20 at $25^{\circ}$, but that of the total dissolved chlorine is much less at small concentrations; thus it becomes less than unity when the chlorine concentration in water is as small as 2.6 millimols per liter.

The Hydrolysis of Chlorine.-See Jakowkin, Z. physik. Chem., 29, 613 (1899).

The Hydrolysis of Iodine and Bromine.-See Bray, ThIS JournaL, 32, 932 (1910); 33, 1485 (1911).

Potassium Tri-iodide.-See Jakowkin Z. physik. Chem., 20, I9 (1896); and Bray and Mackay, This JourNal, 32, 914 (1910).

P. I03, N. 3. Delicacy of the Tests for Halogens. Iodine. $-0.5 \mathrm{mg} . \mathrm{I}_{2}$ was dissolved in $8 \mathrm{cc}$. water and $2 \mathrm{cc} .85 \% \mathrm{H}_{3} \mathrm{PO}_{4}{ }^{5}$ and shaken with $3 \mathrm{cc}$. chloroform: the chloroform had a faint but distinct pink color.

Bromine. $\longrightarrow .7$ and $0.5 \mathrm{mg}$. $\mathrm{Br}_{2}$ were dissolved in $8 \mathrm{cc}$. water and 2 cc. $\mathrm{H}_{3} \mathrm{PO}$, and shaken with $3 \mathrm{cc}$. chloroform: the chloroform layer had a faint but distinct yellow color in each case. The experiment was repeated with $0.3 \mathrm{mg} . \mathrm{Br}_{2}$ : the test was unsatisfactory, since the faint yellow color of the chloroform could be observed only by comparison with pure chloroform. The limit for this test is therefore about $0.5 \mathrm{mg}$. $\mathrm{Br}_{2}$ in $3 \mathrm{cc}$. $\mathrm{CHCl}_{3}{ }^{\circ}$

A third of the aqueous phase in the preceding experiment with $0.7 \mathrm{mg}^{-\mathrm{Br}_{2} \text { was }}$ carefully poured into a test tube containing I cc. $\mathrm{I} \% \mathrm{KI}$ solution, and $\mathrm{I} \mathrm{cc}$. chloroform was added and the mixture shaken. The aqueous solution was practically colorless, but the chloroform showed a very faint pink color. The experiment was repeated

1 Z. physik. Chem., 18, 588-90 (1895).

2 Ibid., 26, I 47 (1898).

${ }^{3}$ Cf. Seidell's "Solubilities."

"Z. physik. Chem., 29, 634-6 (1899).

${ }^{5}$ In the first form of the Procedure, phosphoric acid was added in place of acetic acid, but this could hardly influence the delicacy of the tests.

${ }^{B}$ Cf. C. E. P., rio. 
except that the water-chloroform mixture (containing bromine) was shaken before pouring one-third of it into the KI solution: the aqueous layer was yellow and the chloroform layer pink. This last experiment was repeated with the above mixture containing $0.3 \mathrm{mg}$. $\mathrm{Br}_{2}$ : the aqueous layer was faintly yellow and the chloroform distinctly pink, thus showing that a smaller quantity of bromine could have been detected in this procedure.

Bromine in the First Distillate. $-2 \mathrm{mg} . \mathrm{Br}_{2}$ were added to 5 cc. $\mathrm{Ba}(\mathrm{OH})_{2}$ solution, the mixture was heated, cooled, and acidified with acetic acid, an excess of 1 cc. being added. The mixture having a volume of $10 \mathrm{cc}$. Was shaken with $2-3 \mathrm{cc}$. chloroform: a distinct yellow color Iesulted, which corresponded to about I $\mathrm{mg}$. $\mathrm{Br}_{2}$. The experiment was repeated with $\mathrm{I} \mathrm{mg}$. $\mathrm{Br}_{2}$ : a faint yellow color resulted, which corresponded to about $0.5 \mathrm{mg} . \mathrm{Br}_{2}$. The yellow color disappeared on standing, and special experiments showed that the chief loss was due to volatilization. The experiment was repeated with $10 \mathrm{mg} . \mathrm{Br}_{2}$, the $\mathrm{Br}_{2}$ was extracted 3 times within 3 min., and $\mathrm{KI}$ solution and chloroform added to the aqueous layer: a slight pink coloration resulted, which corresponded to about $0.2 \mathrm{mg} . \mathrm{Br}_{2}$. This showed that the reaction between bromate and bromide in acetic acid solution was so rapid that the apparent loss of bromine in the first experiments could not be attributed to the presence of bromate.

The first experiment in the preceding paragraph was repeated with $0.3 \mathrm{mg} . \mathrm{Br}_{\mathrm{a}}$ and with $0.2 \mathrm{mg} . \mathrm{Br}_{2}$ : the chloroform layer was colorless. The mixture was shaken and one-third of it added to a KI solution: the chloroform layer showed a faint but distinct pink color in the first case, but not in the second.

Chlorine.-An amount of bleaching powder containing I mg. of available chlorine was treated by $\mathrm{P}$. IOI; one-fifth of the distillate was acidified with acetic acid and a few drops of KI solution were added: a distinct liberation of iodine was observed.

A solution containing $20 \mathrm{mg} . \mathrm{Cl}_{2}$ dissolved in $8 \mathrm{cc}$. water and $2 \mathrm{cc}$. $10 \% \mathrm{NaOH}$ solution was acidified with acetic acid and $5 \mathrm{cc}$. $\mathrm{HNO}_{3}(\mathbf{1} .20)$ were added. The mixture was shaken with $2 \mathrm{cc}$. $\mathrm{CHCl}_{3}$ and then with $3 \mathrm{cc}$. The amount of chlorine extracted was estimated to be about $12 \mathrm{mg}$. by adding a little $\mathrm{KI}$ solution to the chloroform. A third treatment with $\mathrm{CHCl}_{3}$ extracted $3 \mathrm{mg}$. $\mathrm{Cl}_{2}$, and the amount remaining in the solution ( $5 \mathrm{mg}$.) was estimated by adding chloroform and a little KI solution to the aqueous phase. The experiment was repeated three times, except that 2 cc. $30 \%$ acetic acid were added instead of $5 \mathrm{cc}$. $\mathrm{HNO}_{3}$ (1.20): the amounts of chlorine extracted in the first two treatments with $\mathrm{CHCl}_{3}$ were estimated to be 4,6 , and $6 \mathrm{mg}$, respectively, in the three experiments.

P. I03, N. 4. Delicacy of the Iodide Test for Nitrous Acid.- 0 I mg. $\mathrm{NO}_{2}$ as $\mathrm{NaNO}_{2}$ was added to Io $\mathrm{cc}$. water and I cc. $30 \%$ acetic acid; $\mathrm{KI}$ solution and chloroform were added and the mixture shaken; the mixture was allowed to stand ro min. and again shaken. A distinct pink color was produced at once, and the depth of color increased on ștanding.

Distribution of Nitrous Acid between Water and Chloroform.-2.0 mg. $\mathrm{NO}_{2}$ as $\mathrm{NaNO}_{2}$ were added to Io $\mathrm{cc}$. water and I cc. acetic acid, and the mixture was extracted twice with chloroform; KI was then added to the chloroform layer: an amount of iodine was liberated which corresponded to less than o.x mg. $\mathrm{NO}_{2}$. The experiment was repeated with $15 \mathrm{mg}$. $\mathrm{NO}_{2}$ : a very distinct test for iodine was obtained when $\mathrm{KI}$ was added to the chloroform layer, and the amount of iodine increased on standing.

P. ro3, N. 5. Action of Bromine and Iodine on Nitrous Acid.-3.5 mg. $\mathrm{Br}_{2}$ in $\mathrm{I}$ cc. water were added to $2 \mathrm{cc}$. of a I\% solution of $\mathrm{NO}_{2}$ as $\mathrm{NaNO}_{2}$ : the color of the bromine disappeared immediately. The same result was obtained in the presence of acetic acid.

To a solution of $\mathrm{I}$ mg. $\mathrm{NO}_{2}$ as $\mathrm{NaNO}_{2}$ in water containing I cc. acetic acid, an ex- 
cess of $I_{2}$ was added. After ro minutes the solution was extracted three times with fresh portions of $\mathrm{CHCl}_{3}$, and the aqueous layer was then shaken with fresh $\mathrm{CHCl}_{3}$ and $\mathrm{KI}$ solution: there resulted a slight pink color, corresponding to $0.2 \mathrm{mg}$. $\mathrm{I}_{2}$.

Io $\mathrm{mg} . \mathrm{NO}_{2}$ as $\mathrm{NaNO}_{2}$ and Io $\mathrm{mg}$. $\mathrm{I}_{2}$ (about one-fifth of the amount necessary to oxidize the nitrite to nitrate) in Io cc. $\mathrm{H}_{2} \mathrm{O}$ were distilled with dilute $\mathrm{H}_{3} \mathrm{PO}_{4}$ according to $P$. IOI. The first distillate was collected in barium hydroxide solution and acidified with acetic acid: it gave no test for nitrous acid with urea by P. 104, and a strong test for $\mathrm{I}_{2}$ on extracting with $\mathrm{CHCl}_{3}$.

P. I $_{3}$, N. 6. See above, N. 2 and 3.

P. I04, N. 2. Delicacy of the Urea Test for Nitrite.- I mg. $\mathrm{NO}_{2}$ as $\mathrm{NaNO}_{2}$ in I cc. $\mathrm{H}_{2} \mathrm{O}$ was added to a $20 \%$ solution of urea in $\mathrm{HCl}$ (1.12): a large number of very minute bubbles formed slowly and rose to the top of the inverted tube. The experiment was repeated with I.O mg.: the bubbles formed quickly and united to a large bubble at the top of the tube. The experiment was repeated with I cc. water which had been shaken with air: a few minute bubbles appeared at once, but not nearly so many as in the experiment,with O.I mg. $\mathrm{NO}_{2}$. The same experiments were tried with a $20 \%$ solution of urea in $\mathrm{H}_{2} \mathrm{SO}_{4}$ ( $\left.\mathrm{r} .2 \mathrm{O}\right)$ : the results were the same.

P. 104, N. 3. Behavior of Halogens in the Urea Test for Nitrite.-Io mg. $\mathrm{Br}_{2}$ were dissolved in $\mathrm{r}$ cc. $\mathrm{Ba}(\mathrm{OH})_{2}$ solution and added to a solution of urea in $\mathrm{HCl}$ : a few minute bubbles (of air) appeared, which corresponded in amount to the test with $\mathbf{I}$ ce. water (preceding paragraph). The experiment was repeated, except that the solution of $\mathrm{Br}_{2}$ in $\mathrm{Ba}(\mathrm{OH})_{2}$ was first acidified with $\mathrm{HCl}$ : the 1 esult was the same. The last experiment was repeated with a solution of chlorine, using a $20 \%$ solution of urea in $\mathrm{H}_{2} \mathrm{SO}_{4}$ : there was no evolution of gas.

P. I05, N. 2. Decomposition of Difficultly Soluble Sulfides by Phosphoric Acid.See C. E. P., roI.

P. I06, N. 2. Delicacy of the Test for Cyanide.-Several separate solutions containing 0.1 and $0.2 \mathrm{mg}$. $\mathrm{CN}$ as $\mathrm{KCN}$ in 1o cc. were tested by P. Io6. A good test was invariably found with $0.2 \mathrm{mg}$. and sometimes with $0.1 \mathrm{mg}$. The experiment with $0.2 \mathrm{mg}$. $\mathrm{CN}$ was repeated except that the $\mathrm{FeCl}_{3}$ was added after boiling: a good test was obtained. The last experiment was twice repeated except that $4.0 \mathrm{cc}$. $10 \% \mathrm{NaOH}$ solution were added instead of $\mathrm{x} .0 \mathrm{cc}$.: the test was very satisfactory but seemed slightly less distinct than before.

P. 106, N. 3. Relative Solubilities of Complex Cyanides. - See Abegg and Bodländer, Z. anorg. Chem., 20, 453 (1899). Böttger, Qual. Analyse, 287, 289, 291, 191, 39 I, 396, and $432-5$ (1908).

P. I06, N. 4. Delicacy of the Test for Cyanide in the Presence of Ferro and Ferricyanide. $-2 \mathrm{mg}$. $\mathrm{CN}$ as $\mathrm{KCN}$ were tested by the procedure described in Note $4:$ a distinct test for cyanide was obtained in the distillate. The experiment was repeated first with $30 \mathrm{mg}$. $\mathrm{Fe}(\mathrm{CN})_{6}$ as $\mathrm{K}_{3} \mathrm{Fe}(\mathrm{CN})_{6}$ and then with $30 \mathrm{mg}$. $\mathrm{Fe}(\mathrm{CN})_{6}$ as $\mathrm{K}_{4} \mathrm{Fe}(\mathrm{CN})_{6}$ : no $\mathrm{CN}$ was found in the distillate in either experiment. The experiment was repeated with a mixture of $2 \mathrm{mg}$. $\mathrm{CN}$ as $\mathrm{KCN}$ and $40 \mathrm{mg}$. $\mathrm{Fe}(\mathrm{CN})_{6}$ as $\mathrm{K}_{3} \mathrm{Fe}(\mathrm{CN})_{6}$ : a distinct test for $\mathrm{CN}$ was obtained in the distillate.

P. xо6, N. 5. The Blue Iron-cyanide Compounds.-Hofmann, Heine and Höchtlen, Liebig's Ann., 337, I (1904).

P. I06, N. 6. Separation of Ferro and Ferricyanides. ${ }^{1-T o} 0.2 \mathrm{mg} . \mathrm{Fe}(\mathrm{CN})_{6}$ as $\mathrm{K}_{4} \mathrm{Fe}(\mathrm{CN})_{6}$ in $10 \mathrm{cc}$. water were added a little acetic acid, $x \mathrm{cc} .4 \% \mathrm{AgNO}_{3}$ solution, and finally excess of $\mathrm{NH}_{4} \mathrm{OH}$ : a small white precipitate formed in the acid solution and did not dissolve on the addition of $\mathrm{NH}_{4} \mathrm{OH}$. This was collected in a filter, washed with water and moistened with a dilute solution of $\mathrm{FeCl}_{3}$ : the precipitate turned blue

${ }^{1}$ See also Böttger, Qual. Analyse, 392, 292 (Igo8). 
at once. The experiment was repeated with $0.2 \mathrm{mg}$. $\mathrm{Fe}(\mathrm{CN})_{6}$ as $\mathrm{K}_{3} \mathrm{Fe}(\mathrm{CN})_{8}$ : A small brown precipitate formed in the acid solution but dissolved in $\mathrm{NH}_{4} \mathrm{OH}$. On acidifying with acetic acid, filtering, washing with water, and adding $\mathrm{FeSO}_{4}$ solution the precipitate turned blue. The last experiment was repeated several times with $50 \mathrm{mg}$. $\mathrm{Fe}(\mathrm{CN})_{6}$ as $\mathrm{K}_{4} \mathrm{Fe}(\mathrm{CN})_{6}$ and I $\mathrm{mg}$. $\mathrm{Fe}(\mathrm{CN})_{6}$ as $\mathrm{K}_{3} \mathrm{Fe}(\mathrm{CN})_{6}$ : the test for ferricyanide failed. $50 \mathrm{mg}$. $\mathrm{Fe}(\mathrm{CN})_{6}$ as $\mathrm{K}_{4} \mathrm{Fe}(\mathrm{CN})_{6}$ and $\mathrm{I} \mathrm{mg}$. $\mathrm{Fe}(\mathrm{CN})_{6}$ as $\mathrm{K}_{3} \mathrm{Fe}(\mathrm{CN})_{6}$ were dissolved in ro cc. water, 2 cc. I\% KI solution, and $2 \mathrm{cc}$. chloroform were added, and $\mathrm{HCl}(\mathrm{r} .20)$ was added drop by drop: on shaking, the chloroform layer became purple.

P. rro. Separation and Detection of the Halogens. Test Analyses.-Known amounts of $\mathrm{KI}, \mathrm{KBr}$, and $\mathrm{KCl}$ were dissolved in about ${ }_{5} \mathrm{cc}$. water, and the mixtures were analyzed by $\mathrm{P}$. I Io. The following table shows the milligrams of $\mathrm{I}, \mathrm{Br}$, and $\mathrm{Cl}$ taken in each experiment, and the results obtained. The letter $\mathrm{S}$ signifies that the test or the blank was satisfactory. This was found to be true in every case.

\begin{tabular}{|c|c|c|c|c|c|c|c|c|c|}
\hline Expt. & 1. & 2. & $\begin{array}{c}3 . \\
100 \mathrm{~S}\end{array}$ & 4. & 5. & 6. & 7. & 8. & $\begin{array}{l}9 . \\
\text { o S }\end{array}$ \\
\hline $\mathrm{Br}$ & $0-$ & $0-$ & o $S$ & I $\mathrm{S}$ & o $S$ & I $S$ & oS & $100 \mathrm{~S}$ & $100 \mathrm{~S}$ \\
\hline $\mathrm{Cl}$. & $0-$ & $0-$ & o $S$ & os & $500 \mathrm{~S}$ & $500 \mathrm{~S}$ & I $S$ & os & I $\mathrm{S}$ \\
\hline
\end{tabular}

Liberation of Bromine in the Iodide Test.-To solutions containing $100 \mathrm{mg} . \mathrm{Br}$ as $\mathrm{KBr}$ dissolved in $\mathrm{I}_{5} \mathrm{cc}$. water were added $5 \mathrm{cc} . \mathrm{CS}_{2}$, known amounts of a ro\% sodium acetate solution, I cc. $30 \%$ acetic acid, and $20 \mathrm{cc}$. o. I $N \mathrm{KMnO}_{\text {; solution; after }}$ I hour the mixtures were shaken, the $\mathrm{CS}_{2}$ was drawn off, and the amount of $\mathrm{Br}_{2}$ liberated was estimated from the color of the $\mathrm{CS}_{2}$ : with $\mathrm{r} \mathrm{cc}$. 10\% acetate solution about $5 \mathrm{mg}$. $\mathrm{Br}_{2}$ were liberated; with $2 \mathrm{cc}$. about I mig.; and with $5 \mathrm{cc}$. not enough $\mathrm{Br}_{2}$ to give a color to the $\mathrm{CS}_{2}$. In the last experiment, the proportion of acetate to acetic acid was the same as in the Procedure, but the $\mathrm{KMnO}_{4}$ added and the time allowed was much greater. The result obtained therefore shows that there is no danger of liberating $\mathrm{Br}_{2}$ under the conditions of the Procedure.

Action of Permanganate on Iodide to Form Iodate.-50 $\mathrm{mg}$. I as $\mathrm{KI}$ in a volume of $\mathrm{I}_{5} \mathrm{cc}$. were treated with $5 \mathrm{cc}$. $10 \% \mathrm{NaC}_{2} \mathrm{H}_{3} \mathrm{O}_{2}$, I cc. $30 \% \mathrm{HC}_{2} \mathrm{H}_{3} \mathrm{O}_{2}$, and ${ }_{5} \mathrm{cc}$. 0 . I $N \mathrm{KMnO}_{4}$ solution (in the absence of $\mathrm{CS}_{2}$ ). After standing ro minutes the mixture was shaken several times with $\mathrm{CS}_{2}$ until the last $\mathrm{CS}_{2}$ portion was colorless. The water layer was treated with $\mathrm{H}_{2} \mathrm{SO}_{3}$ until colorless, allowed to stand 5 minutes, and then tested with $\mathrm{CS}_{2}$ and $\mathrm{KMnO}_{4}$ as described in the procedure: a very satisfactory test for iodide was obtained. This shows that iodate had been formed by the action of $\mathrm{KMnO}_{4}$ on iodine (or iodide), and that the iodate was reduced by the treatment with $\mathrm{H}_{2} \mathrm{SO}_{3}$. The experiment was repeated with I $\mathrm{mg}$. I as $\mathrm{KI}$ : no iodine was extracted by the first treatment with $\mathrm{CS}_{2}$, thus showing that the initial presence of $\mathrm{CS}_{2}$ and shaking are essential if a small amount of iodide is to be detected when excess of $\mathrm{KMnO}_{4}$ is added. The experiment with $50 \mathrm{mg}$. I as $\mathrm{KI}$ was repeated except that $\mathrm{CS}_{2}$ was initially present and that the iodine was extracted at once instead of after to minutes: some iodate was formed, but much less than in the above experiment.

Effect of Iodate on the Bromide Test.-A solution containing $100 \mathrm{mg} . \mathrm{Br}$ as $\mathrm{KBr}$ and $500 \mathrm{mg}$. $\mathrm{KIO}_{3}$ in $20 \mathrm{cc}$. was treated with $5 \mathrm{cc} .10 \% \mathrm{NaC}_{2} \mathrm{H}_{3} \mathrm{O}_{2}$ and $\mathrm{I} \mathrm{cc} .30 \% \mathrm{HC}_{2} \mathrm{H}_{3} \mathrm{O}_{2}$ and allowed to stand Io minutes. The mixture was shaken with $5 \mathrm{cc}$. $\mathrm{CHCl}_{3}$, and the $\mathrm{CHCl}_{3}$ layer was drawn off and tested with a few drops of $\mathrm{KI}$ : there was no color, thus showing that no bromine would be liberated in the iodide test owing to the presence of iodate. $5 \mathrm{cc}$. chloroform and $5 \mathrm{cc} . \mathrm{H}_{2} \mathrm{SO}_{4}$ ( $\mathrm{I} .2 \mathrm{O}$ ) were then added to the aqueous layer: bromine was liberated in latge amount. The experiment was then repeated with I $\mathrm{mg}$. $\mathrm{Br}$ as $\mathrm{KBr}$ and $500 \mathrm{mg}$. $\mathrm{KIO}_{3}$. After adding the $\mathrm{H}_{2} \mathrm{SO}_{4}$ the $\mathrm{CHCl}_{3}$ layer showed the bromine color, and iodine was liberated on adding a few drops $\mathrm{KI}$ to the 
$\mathrm{CHCl}_{3}$ layer. This shows that the presence of iodate does not interfere with the test for bromine.

Liberation of Chlorine in the Bromide Test.-500 $\mathrm{mg} . \mathrm{Cl}$ as $\mathrm{NaCl}$ in a volume of $\mathrm{r}_{5}$ cc. were treated with I cc. $\mathrm{H}_{2} \mathrm{SO}_{4}$ (1.20) and $5 \mathrm{cc} .0 .2 \mathrm{~N} \mathrm{KMnO}_{4}$, allowed to stand 30 minutes, and extracted with $5 \mathrm{cc}$. $\mathrm{CHCl}_{3}$ : the $\mathrm{CHCl}_{3}$ was colorless, and on adding a few drops of $\mathrm{KI}$ the small amount of iodine liberated was estimated to correspond to about $0.3 \mathrm{mg}$. $\mathrm{Cl}_{2}$. A solution containing $500 \mathrm{mg}$. $\mathrm{Cl}$ as $\mathrm{NaCl}$ and $100 \mathrm{mg} . \mathrm{KIO}_{3}$ in $15 \mathrm{cc}$. was treated with 2 cc. $\mathrm{H}_{2} \mathrm{SO}_{4}$ (I.2O) and ${ }_{5} \mathrm{cc}$. O.I $N \mathrm{KMnO}_{4}$ solution, and $5 \mathrm{cc} . \mathrm{CHCl}_{3}$ were added: the $\mathrm{CHCl}_{3}$ layer remained colorless. After 5 minutes the mixture was shaken, the $\mathrm{CHCl}_{3}$ drawn off and treated with a few drops of $\mathrm{KI}$ solution: the purple color showed the presence of about $0.2 \mathrm{mg} . \mathrm{Cl}_{2} .5 \mathrm{cc}$. more $\mathrm{CHCl}_{3}$. were then added and tested in the same way with $\mathrm{KI}$ after 25 minutes: the amount of iodine liberated showed the presence of about $\mathrm{I} \mathrm{mg} . \mathrm{Cl}_{2}$. These experiments show that the liberation of chlorine in the bromice test is very slow, even in the presence of iodate and of large amounts of chloride. There is, therefore, no danger of oxidizing a small amount of chloride completely to chlorine.

Complete Removal of Bromide by Boiling.-A solution of $150 \mathrm{mg} . \mathrm{Br}$ as $\mathrm{KBr}$ in 20 cc. was treated with 2 cc. of $\mathrm{H}_{2} \mathrm{SO}_{4}(\mathrm{I} .20)$ and $\mathrm{I} 8 \mathrm{cc}$. of $0.2 \mathrm{~N} \mathrm{KMnO}_{4}$, and boiled for about 2 minutes until the odor of bromine could no longer be detected. The solution was filtered and treated with 2 cc. of $\mathrm{H}_{2} \mathrm{SO}_{4}$ and 5 cc. of $\mathrm{KMnO}_{4}$, allowed to stand 5 minutes, and extracted with $\mathrm{CHCl}_{3}$ : no bromine was found.

Non-Removal of Chloride by Boiling with Permanganate in the Presence of Sulfurie Acid.- $\mathrm{I} \mathrm{mg}$. $\mathrm{Cl}$ as chloride in $20 \mathrm{cc}$. was treated with $3 \mathrm{cc} \mathrm{H}_{2} \mathrm{SO}_{4}(\mathrm{I} .20)$ and $\mathrm{I}_{5} \mathrm{cc}$. of $0.2 N \mathrm{KMnO}_{4}$, boiled for 3 minutes, and extracted with $\mathrm{CHCl}_{3}$; the water layer was diluted, treated with $\mathrm{H}_{2} \mathrm{SO}_{3}$ to decolorize the excess of $\mathrm{KMnO}_{4}$, and to it $\mathrm{AgNO}_{3}$ and $\mathrm{HNO}_{3}$ were added: a distinct precipitate was formed, while a blank test carried out in a similar manner gave only a slight turbidity at this point.

Non-Effect of Thiocyanate on the Test for Chloride.-A solution of $20 \mathrm{mg}$. SCN as $\mathrm{KSCN}$ in $20 \mathrm{cc}$. was treated with $3 \mathrm{cc}$. of $\mathrm{H}_{2} \mathrm{SO}_{4}(\mathrm{r} .2 \mathrm{O}$ ) and with $\mathrm{I2}$ cc. of $0.2 \mathrm{~N}$ $\mathrm{KMnO}_{4}$ : this was decolorized as fast as it was added, with separation of $\mathrm{MnO}_{2}$; and the clear colorless filtrate gave no color on adding $\mathrm{FeCl}_{3}$, nor any precipitate on treating with $\mathrm{HNO}_{3}$ and $\mathrm{AgNO}_{3}$.

Delicacy of the Color Test for Free Bromine in Chloroform and Other Solvents.$\mathrm{I}, 0.5,0.3$, and $0.0 \mathrm{mg}$. $\mathrm{Br}$ as $\mathrm{KBr}$ in $20 \mathrm{cc}$. water were each treated with $2 \mathrm{cc}$. of $\mathrm{H}_{2} \mathrm{SO}_{4}$ (I.20) and I cc. of $0.2 \mathrm{~N} \mathrm{KMnO}_{4}$; after standing Io minutes each solution was extracted with $5 \mathrm{cc}$. $\mathrm{CHCl}_{3}$, and the chloroform layer washed once with water: the $\mathrm{I} \mathrm{mg}$. sample gave a pronounced color to the $\mathrm{CHCl}_{3}$, the $0.5 \mathrm{mg}$. one gave a distinct but faint color. Similar experiments with $\mathrm{CS}_{2}$ and $\mathrm{CCl}_{4}$ gave similar results; but the tests with these solvents seemed to be a little less delicate than with $\mathrm{CHCl}_{3}$.

P. III, N. I. Delicacy of Nitrate Test.-0.2 mg. $\mathrm{NO}_{3}$ as $\mathrm{NaNO}_{3}$ in Io cc. water were treated by $\mathrm{P}$. II $\mathrm{I}$ : a distinct liberation of iodine in the distillate resulted on adding $\mathrm{H}_{2} \mathrm{SO}_{4}$ and $\mathrm{KI}$. $2 \mathrm{mg}$. $\mathrm{NO}_{3}$ were treated by $\mathrm{P}$. ror, and one-third of the distillate from this procedure was treated by P. II : a good test for nitrate was obtained.

P. III, N. 2. Interference of Iodide with the Nitrate Test and Its Removal.-50 mg. I as KI were put through P. I II. On making the distillate acid a large amount of iodine was liberated.

$50 \mathrm{mg}$. I as $\mathrm{KI}$ and $0.3 \mathrm{mg}$. $\mathrm{NO}_{3}$ as $\mathrm{NaNO}_{3}$ in $\mathrm{Io} \mathrm{cc}$. water were treated with $\mathrm{I}_{5}$ cc. of a nearly saturated $\mathrm{AgC}_{2} \mathrm{H}_{3} \mathrm{O}_{2}$ solution, boiled I minute, allowed to stand a short time, and filtered; and the filtrate was treated by P. I I I : on making the distillate acid with $\mathrm{H}_{2} \mathrm{SO}$, no iodine was liberated and on adding a few drops of $\mathrm{KI}$ solution a distinct yellow color was given to the mixture. This experiment was repeated with $50 \mathrm{mg}$. 
I and no $\mathrm{NO}_{3}$ : a little color due to liberated iodine was observed in the final test, but distinctly less than in the preceding experiment with $0.3 \mathrm{mg} . \mathrm{NO}_{3}$. This small test was later shown to be due to a trace of nitrate existing as impurity in the $\mathrm{AgC}_{2} \mathrm{H}_{3} \mathrm{O}_{2}$ used.

Non-Interference of Cyanide in the Nitrate Test.-A solution of $100 \mathrm{mg} . \mathrm{CN}$ as $\mathrm{KCN}$ and $1 \mathrm{mg} . \mathrm{NO}_{3}$ as $\mathrm{NaNO}_{3}$ in Io $\mathrm{cc}$. water was treated by P. I II: a small but distinct color resulted in the distillate on adding acid and $\mathrm{KI}$. The experiment was repeated with IOQ $\mathrm{mg}$. $\mathrm{CN}$ as $\mathrm{KCN}$ and no $\mathrm{NO}_{3}$ in Io cc. water: the distillate treated with acid and $\mathrm{KI}$ gave no color.

Interference of Thiocyanate in the Nitrate Test.-0.5 mg. $\mathrm{NO}_{3}$ as $\mathrm{NaNO}_{3}$ and 100 mg. SCN as $\mathrm{KSCN}$ in Io cc. water were treated by $\mathrm{P}$. I I : the distillate smelled strongly of $\mathrm{H}_{2} \mathrm{~S}$ and gave no liberation of iodine when treated with acid and $\mathrm{KI}$.

P. II2, N. I. Delicacy of Test for Sulfate.-See C. E., P. IOI, N. 5 and 9.

P. II3, N. 2. Delicacy of the Borate Test.-2 mg. $\mathrm{BO}_{2}$ as $\mathrm{Na}_{2} \mathrm{~B}_{4} \mathrm{O}_{7}$ were treated by P. II3: a distinct color resulted. On setting fire to the orange tinted solution to which the turmeric had been added, no green color was noticeable in the flame. The experiment was repeated with $5 \mathrm{mg}$. $\mathrm{BO}_{2}$ : a good test with turmeric was obtained; and a flash of green could be seen just at the moment of setting fire to the solution.

P. II3, N. 2. Use of Ethyl Alcohol in the Borate Test.-5 mg. $\mathrm{BO}_{2}$ as $\mathrm{Na}_{2} \mathrm{~B}_{4} \mathrm{O}_{7}$ were treated by $\mathrm{P}$. II 3 , except that $\mathrm{C}_{2} \mathrm{H}_{5} \mathrm{OH}$ was substituted for the $\mathrm{CH}_{3} \mathrm{OH}$ : the color obtained with turmeric was so slight as to be doubtful.

P. II4. The Test for Fluoride,-This method was described by Berzelius. The directions in P. II4 are similar to those given by Brush-Penfield, Determinative Mineralogy and Blowpipe Analysis.

A known small amount of $\mathrm{F}$ as powdered fluorite, $\mathrm{CaF}_{2}$, mixed with a few milligrams powdered $\mathrm{SiO}_{2}$ and about $50 \mathrm{mg}$. powdered $\mathrm{KHSO}_{4}$, was heated in a small bulb blown on a tube of $5 \mathrm{~mm}$. bore, and was treated as described in the Procedure: there was a ring of $\mathrm{SiO}_{2}$ in the tube about $4 \mathrm{~cm}$. from the bulb, and the etching in the lower part of the tube was very distinct even in the experiment with $0.5 \mathrm{mg}$. F. The experiment with $0.5 \mathrm{mg}$. $\mathrm{F}$ as $\mathrm{CaF}_{2}$ was repeated with no silica but in the presence of 500 $\mathrm{mg}$. $\mathrm{KHSO}_{4}$ and with a large bulb: the ring test was small but distinct, but the etching test was unsatisfactory. Several experiments were tried in the absence of $\mathrm{CaF}_{2}$ : satisfactory blanks were always obtained.

The experiment was repeated with $20 \mathrm{mg}$. $\mathrm{CaF}_{2}, 20 \mathrm{mg}$. $\mathrm{SiO}_{2}$ and about $100 \mathrm{mg}$. $\mathrm{KHSO}_{4^{*}}$ The tube was closed by a small rubber stopper through which a small capillary tube moistened on the inside passed to about $4 \mathrm{~cm}$. from the bulb: there was a heavy ring of deposited solid in the entrance to the capillary and on the wall of the outside tube near the end of the capillary tube. This indicates that there is no tendency for the $\mathrm{SiF}_{1}$ to escape from the tube. The experiment was repeated with 0.5 $\mathrm{mg}$. $\mathrm{F}$ as $\mathrm{CaF}_{2}$ : there was a distinct ring test on the wall of the large tube, but none in the capillary tube. There is therefore no advantage in inserting the moist capillary.

P. II4. Modification of the Fluoride Test.-4, 2 and I $\mathrm{mg} . \mathrm{F}$ as solid $\mathrm{CaF}_{2}$ were mixed with 50-100 $\mathrm{mg}$. ignited precipitated $\mathrm{SiO}_{2}$ in a dry weighing tube, and 8-ro drops $\mathrm{H}_{2} \mathrm{SO}_{4}$ (1.84) were added; a wet glass rod with a drop of water hanging from it was suspended from a stopper in the tube, and the nixture was warmed gently: upon heating there was in each case a distinct effervescence, and in the $4 \mathrm{mg}$. and $2 \mathrm{mg}$. experiments the wet walls of the rod, but not the drop of water, became distinctly opaque; in the I mg. experiment, the opaqueness produced was so slight as to be doubtful, thus showing that this form of the test is less delicate than that described in the Procedure.

P. II6, N. 4. Reaction between Sodium and Certain Insoluble Substances.-See Mulliken, Identification of Organic Compounds, Vol. I. 
$2 \mathrm{mg}$. AgI were fused with sodium as described in P. II $6, \mathrm{~N} .4$, and the solution tested by $\mathrm{P}$. I Io: a distinct test for iodide was obtained. $16 \mathrm{mg}$. $\mathrm{BaSO}_{4}$ were fused with sodium, and the acetic acid solution was treated by P. I05: a large yellow precipitate of CdS formed. The last experiment was repeated with $4.4 \mathrm{mg}$. S as $\mathrm{MoS}_{2}$ (molybdenite): a CdS precipitate was obtained, whose size indicated the complete decomposition of the $\mathrm{MoS}_{2}$.

P. II7, N. 2 and 4. Delicacy of the Test for Hypochlorite.-In each experiment a known amount of an alkaline $\mathrm{NaClO}$ solution (made by treating a known weight of bleaching powder with a small excess of $\mathrm{Na}_{2} \mathrm{CO}_{3}$ solution to which some $\mathrm{NaOH}$ was added and filtering) was diluted to $5 \mathrm{cc}$. with water; I cc. $30 \%$ HAc and then $2 \mathrm{cc}$. $20 \% \mathrm{PbAc}_{2}$ soln. were added, and the mixtures were heated to boiling and allowed to stand for ten minutes: in the experiments with less than $0.5 \mathrm{mg} . \mathrm{ClO}$, the solutions remained perfectly clear. In that with $0.5 \mathrm{mg}$. $\mathrm{ClO}$ a small, brown precipitate appeared within ten minutes. With I.O mg. ClO the brown precipitate was very distinct in one minute, and with ro $\mathrm{mg}$. it formed while the mixture was being heated.

The experiments were repeated, except that no acetic acid was added: the results were the same, except that small white precipitates of $\mathrm{Pb}(\mathrm{OH})_{2}$ always formed, and that in experiments with 0.2 and $0.3 \mathrm{mg}$. $\mathrm{ClO}$ these turned brown in ro or 15 minutes.

The experiments with and without acetic acid were repeated, except that after the addition of the lead acetate the mixtures were allowed to stand at room temperature: in experiments with $50 \mathrm{mg}$. $\mathrm{ClO}$ the brown precipitate formed almost immediately, while with ro mg. $\mathrm{ClO}$ it appeared within I to 5 minutes.

Effect of the Presence of Nitric Acid.-The experiments described in the preceding section were repeated, except that $0.5 \mathrm{cc}$. $\mathrm{HNO}_{3}$ (1.20) was added instead of acetic acid and $2 \mathrm{cc}$. $10 \% \mathrm{~Pb}\left(\mathrm{NO}_{3}\right)_{2}$ solution instead of lead acetate solution: the solutions remained clear and colorless even in the experiment with $50 \mathrm{mg}$. ClO. These experiments were repeated except that no nitric acid was added: white precipitates of $\mathrm{Pb}(\mathrm{OH})$, were formed and turned brown as in the experiments with $\mathrm{PbAc}_{2}$ in the absence of acetic acid, but the limit of detectability was about I $\mathrm{mg}$. $\mathrm{ClO}$.

Solubility of Lead Hypochlorite.-To Io $\mathrm{mg}$. $\mathrm{ClO}$ as $\mathrm{NaClO}$ dissolved in $10 \mathrm{cc}$. slightly alkalin solution were added 2 cc. $20 \% \mathrm{~Pb}(\mathrm{Ac})_{2}$ solution; the mixture was shaken and filtered: the white precipitate turned brown on the filter. The filtrate was heated to boiling: a dark brown precipitate formed quickly, and showed the presence of at least $5 \mathrm{mg}$. $\mathrm{ClO}$ in the filtrate. It is to be noted that there is no evidence that any $\mathrm{Pb}(\mathrm{ClO})_{2}$ precipitated.

Effect of the Presence of Carbonate and of the Absence of Excess of Lead Acetate.-In each experiment a known amount of $\mathrm{ClO}$ as $\mathrm{NaClO}$ was dissolved in $10 \mathrm{cc} .1 \% \mathrm{Na}_{2} \mathrm{CO}_{3}$ solution in a casserole; 2 to $3 \mathrm{cc}$. $20 \% \mathrm{PbAc}_{2}$ solution were added, and the mixture was boiled vigorously: the brown color showed at once on heating with ro mg. $\mathrm{ClO}$, quickly with $2 \mathrm{mg}$. $\mathrm{ClO}$, and was slight but distinct with I $\mathrm{mg}$. $\mathrm{ClO}$; in the last case it became more distinct on vigorous boiling. In some of these cases a portion of the solution was filtered off and $\mathrm{Na}_{2} \mathrm{CO}_{8}$ added: the formation of a white precipitate showed the presence of lead salt in excess.

The experiment with $10 \mathrm{mg}$. ClO was repeated, except that only I cc. $5 \% \mathrm{PbAc}_{2}$ was added: the test failed. In this and in several other experiments in which the test failed, the solutions were filtered off and shown not to contain lead in excess.

P. II7, N. 3. Action of Lead Salts on Peroxides and on Hydrogen Peroxide.-0. I g. $\mathrm{Na}_{2} \mathrm{O}_{2}$ was dissolved in 1o cc. water and $2 \mathrm{cc} .20 \% \mathrm{PbAc}_{2}$ solution added: a brown precipitate formed at once, and remained when the mixture was boiled. The experiment was repeated with about $\mathrm{I} \mathrm{mg}$. $\mathrm{Na}_{2} \mathrm{O}_{2}$ : a brown turbidity appeared at once. The experiment with I mg. $\mathrm{Na}_{2} \mathrm{O}_{2}$ was repeated, except that the $\mathrm{PbAc}_{2}$ solution was poured 
over the dry $\mathrm{Na}_{2} \mathrm{O}_{2}$ : a dark brown, almost black, precipitate formed at once. The experiment with $\mathrm{I}$ mg. $\mathrm{Na}_{2} \mathrm{O}_{2}$ was repeated in the presence of $0.5 \mathrm{cc}$. $10 \% \mathrm{Na}_{2} \mathrm{CO}_{3}$ solution: the brown color could not be detected in the large white precipitate.

The experiment with o.I g. $\mathrm{Na}_{2} \mathrm{O}_{2}$ was repeated, except that the solution was made slightly acid with acetic acid (the presence of $\mathrm{H}_{2} \mathrm{O}_{2}$ in the solution was shown by adding a drop of a titanium sulfate solution to a small portion of the mixture): lead acetate solution gave no precipitate even when the mixture was boiled.

To I cc. $30 \% \mathrm{H}_{2} \mathrm{O}_{2}$ was added I cc. $20 \% \mathrm{PbAc}_{2}$ solution: a brown turbidity appeared, but violent evolution of gas began almost at once and the brown color vanished. On heating the mixture to boiling, no precipitate formed. The experiment was repeated except that I drop $30 \%$ acetic acid was also added: the solution remained clear at room temperature, but on heating a violent evolution of gas began, and the mixture remained clear and colorless.

P. II8, N. I. The Test for Chlorate. -5 cc. of the $\mathrm{H}_{2} \mathrm{SO}_{3}$ solution used in the following experiments were equivalent to about I $5 \mathrm{cc}$. of the $4 \% \mathrm{AgNO}_{3}$ solution. Blank experiments were performed in which ro cc. $4 \% \mathrm{AgNO}_{3}$ solution, $80 \mathrm{cc}$. water, and known amounts of $\mathrm{HNO}_{3}(\mathrm{I} .2 \mathrm{O})$ were mixed and $5 \mathrm{cc} . \mathrm{H}_{2} \mathrm{SO}_{3}$ solution added: a large white precipitate of $\mathrm{Ag}_{2} \mathrm{SO}_{3}$ formed in the presence of $3 \mathrm{cc}$. $\mathrm{HNO}_{3}$ ( $\mathrm{I} .20$ ), but none in the presence of $4 \mathrm{cc}$. or $5 \mathrm{cc}$, even on heating to boiling. The experiments were repeated with 10-20 cc. water, instead of $80 \mathrm{cc}$.: the results were the same.

The experiment with $5 \mathrm{cc} . \mathrm{HNO}_{3}(1.20)$ in $100 \mathrm{cc}$. was repeated in the presence of I mg. $\mathrm{ClO}_{3}$ as $\mathrm{KClO}_{3}$ : within 3 minutes at room temperature the mixture was turbid, and within ten minutes the precipitate was very distinct. This experiment was repeated in the presence of $25 \mathrm{cc} . \mathrm{HNO}_{3}(\mathbf{1} .20)$ instead of $5 \mathrm{cc}$ : the precipitate of $\mathrm{AgCl}$ formed somewhat more quickly than in the experiment with less acid, and was very distinct in less than 3 minutes. The experiment with $5 \mathrm{cc}$. $\mathrm{HNO}_{8}$ in $100 \mathrm{cc}$. was repeated in the presence of $3 \mathrm{mg}$. $\mathrm{ClO}_{3}$ as $\mathrm{KClO}_{3}$ : the precipitate appeared almost at once and increased rapidly in amount.

Reduction of Hypochlorite by Arsenite. -The hypochlorite solution used was that described above in C. E., P. I I , N. 2, and was two weeks old. 100 $\mathrm{mg}$. $\mathrm{ClO}$ as $\mathrm{NaClO}$ were dissolved in $50 \mathrm{cc}$. water and Io cc. $\mathrm{HNO}_{3}$ (1.20), 10 cc. 10\% alkalin $\mathrm{Na}_{3} \mathrm{AsO}_{3}$ solution were added slowly, and at intervals a few drops of the solution were placed on filter paper moistened with KI solution. Even with this large excess of arsenite a very faint test for iodine was still obtained, doubtless due to the equilibrium, $2 \mathrm{HI}+$ $\mathrm{H}_{3} \mathrm{AsO}_{4}=\mathrm{H}_{3} \mathrm{AsO}_{3}+\mathrm{I}_{2}+\mathrm{H}_{2} \mathrm{O}$. $\mathrm{AgNO}_{3}$ solution was then added in excess, the precipitate filtered off, and the filtrate tested for chlorate by P. I 8: a precipitate of $\mathrm{AgCl}$ was obtained which was estimated to correspond to 3 to $5 \mathrm{mg}$. $\mathrm{ClO}_{3}$, which amount was probably present in the original NaClO solution.

P. Ir8, N. 2. Action of $\mathrm{H}_{2} \mathrm{~S}$ on $\mathrm{AgBr}$ Suspended in Water.-To $100 \mathrm{mg} . \mathrm{Br}$ as freshly precipitated $\mathrm{AgBr}$ were added about $70 \mathrm{cc}$. water and a few drops $\mathrm{HNO}_{3}$ (I.20), and $\mathrm{H}_{2} \mathrm{~S}$ was passed into the mixture for Io or $\mathrm{I}_{5}$ minutes: the white precipitate turned black almost immediately. The liquid was decanted through a filter, and the precipitate was treated repeatedly by the same process, except that in the fourth and fifth treatments the mixture was heated to boiling before filtration. Each filtrate was boiled until the $\mathrm{H}_{\mathrm{g}} \mathrm{S}$ was expelled, $\mathrm{AgNO}_{3}$ solution was added, and the amounts of $\mathrm{Br}$ extracted by the successive treatments were estimated from the size of the precipitates to be about 50,20 , IO, I 5 and $3 \mathrm{mg}$, respectively. This shows that about half the bromide had been extracted in the first treatment, even in the cold. The experiment was repeated with I ing. $\mathrm{Br}$ as $\mathrm{AgBr}$ : a good test for bromide resulted. A blank experiment was also made, which gave a very satisfactory negative result.

roo $\mathrm{mg}$. $\mathrm{Br}$ as freshly precipitated $\mathrm{AgBr}$ were suspended in $25 \mathrm{cc}$. water (not con- 
taining any $\mathrm{HNO}_{3}$ ), $\mathrm{H}_{2} \mathrm{~S}$ was passed through for 15 minutes, the mixture heated to boiling, the liquid decanted through a filter, and $\mathrm{AgNO}_{3}$ added: a precipitate of $\mathrm{AgBr}$ resulted which was apparently nearly as large as the amount taken. The residue from the $\mathrm{H}_{2} \mathrm{~S}$ treatment was washed and heated with $\mathrm{HNO}_{3}$ ( 1 .20): the residue (of $\mathrm{AgBr}$ and $\mathrm{S}$ ) was less than one-fifth of the amount taken.

P. II9. Delicacy of the Suifite and Thiosulfate Tests. $-2 \mathrm{mg} . \mathrm{SO}_{3}$ as $\mathrm{Na}_{2} \mathrm{SO}_{3}$ were dissolved in $8 \mathrm{cc}$. water and $2 \mathrm{cc}$. $10 \% \mathrm{Na}_{2} \mathrm{CO}_{3} ; 3 \mathrm{cc}$. $10 \% \mathrm{Sr}\left(\mathrm{NO}_{3}\right)_{2}$ solution were added, the mixture was acidified with acetic acid and the clear solution heated to boiling: a finely divided precipitate separated at once. After 15 minutes this was filtered off and treated as described in the Procedure: the precipitate of $\mathrm{BaSO}_{4}$ was distinct within 5 minutes after adding the bromine. The experiment was repeated twice with I mig. $\mathrm{SO}_{3}$ as $\mathrm{Na}_{2} \mathrm{SO}_{3}$ : in each case the clear solution became slightly turbid on boiling, and a small but distinct confirmatory test was obtained. The experiment was repeated several times in the absence of sulfite: the solutions remained clear on boiling. In some cases a flocculent precipitate of $\mathrm{SrCO}_{3}$ formed while the mixture was being heated, but it dissolved on the addition of two or three drops of acetic acid.

Solutions containing $3 \mathrm{mg} . \mathrm{S}_{2} \mathrm{O}_{3}$ as $\mathrm{Na}_{2} \mathrm{~S}_{2} \mathrm{O}_{3}$ in $8 \mathrm{cc}$. water and $2 \mathrm{cc}$. $10 \% \mathrm{Na}_{2} \mathrm{CO}_{3}$ were treated as described in the preceding paragraph. To the resulting clear solutions were added $2 \mathrm{cc} . \mathrm{HCl}(\mathrm{x}, 20)$, and the mixtures were heated to boiling and allowed to stand: white precipitates of sulfur usually appeared within half an hour. The experiment was repeated twice with $2 \mathrm{mg} . \mathrm{S}_{2} \mathrm{O}_{3}$; the solutions remained clear for about three hours, but were distinctly turbid in four hours. The experiment was repeated twice with I mg. $\mathrm{S}_{2} \mathrm{O}_{3}$ : the solutions appeared to be nearly clear on standing over night, but became turbid when the mixtures were then shaken and allowed to stand half an hour longer. These experiments were repeated with an excess of $8 \mathrm{cc}$. $\mathrm{HCl}$ ( 1.20 ) instead of $2 \mathrm{cc}$ : in an experiment with $3 \mathrm{mg} . \mathrm{S}_{2} \mathrm{O}_{3}$ the solution was clear after I hour, but became turbid over night, while in the experiments with 2 and I mg. no precipitates formed even on standing 24 hours. This shows that a large excess of acid interferes with the test.

To $\mathrm{I} \mathrm{mg} . \mathrm{S}_{2} \mathrm{O}_{3}$ as $\mathrm{Na}_{2} \mathrm{~S}_{2} \mathrm{O}_{3}$ dissolved in Io cc. water were added 2 cc. $\mathrm{HCl}$ (I.I2); the mixture was heated to boiling and allowed to stand: there was a small but distinct turbidity in half an hour which increased on standing.

Effect of Excess of Acetic Acid on the Thiosulfate Test.-100 mig. $\mathrm{S}_{2} \mathrm{O}_{3}$ as $\mathrm{Na}_{2} \mathrm{~S}_{2} \mathrm{O}_{3}$ in $8 \mathrm{cc}$. water and $2 \mathrm{cc}$. IO $\% \mathrm{Na}_{2} \mathrm{CO}_{3}$ solution were tested for sulfite by the process described in the preceding section: the solution remained clear on boiling. The experiment was repeated, except that an excess of $5 \mathrm{cc}$. $30 \%$ acetic acid was added: the solution became turbid when it was boiled, but the small sulfur precipitate did not increase in amount when the mixture was set aside at room temperature. The experiment was repeated with an excess of only $1 \mathrm{cc}$. $30 \%$ acetic acid: a faint turbidity appeared when the mixture was boiled; the mixture was slightly turbid after I hour, but was clear after three hours.

[CONTribution from the Institute of Animal Nutrition of the Pennsyluania STATE COLLEGE.]

\title{
ADIABATIC DEVICE FOR BOMB CALORIMETER.
}

\author{
BY J. A. FRIES.
}

Received January 29, 1912.

The value of an adiabatic equipment to a bomb calorimeter lies in the fact that such a device, if only simple enough, may be a means both of saving time and of greater accuracy in determining the heat of com- 